\title{
SOBRE LOS PERIODOS DE LA VIDA HUMANA EN LA LIRICA ARCAICA Y LA TRAGEDIA GRIEGA (II)
}

In the second part of this paper the authoress analyses the formal structures and the lexical recurrence of the Greek Tragedy and, so, she establishes respectively the distinctive features of the youth, the maturity and the old age. And on the functional level, she also establishes the existence of a bond between the ethical value of the different ages of the human life and the crisis of the polis foreboding of the Hellenistic Age.

4. Estructuras formales de la tragedia

a) D a tos

Como anunciaba en la primera parte ${ }^{1}$, en la tragedia es frecuente hallar la estructura de forma que consiste en contraponer a personas de dos edades, ocasionalmente incluso de tres, sea en composición dialógica o en la resis alternada. Es a su estudio al que vamos a dedicarnos a continuación ${ }^{2}$.

Desde un punto de vista puramente formal, éstos son los datos con los que contamos ${ }^{3}$.

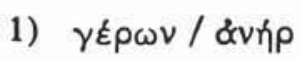

1 Coro-Creonte

2 Tiresias-Creonte

3 Feres-Admeto

4 Tiresias, Cadmo-Penteo
Antigona 155-222; 278-314; $1091-1114$ y 1261 1352

Antigona 988-1090

Alcestis $606-742$

Bacantes 215-369

1 Cf. EMERITA 51, 1983, pp. 63-95.

2 En una publicación colectiva titulada The Conflict of Generations in ancient Greece and Rome, ed. Stephen Bertman, Amsterdam 1976, hay dos artículos, uno dedicado al conflicto generacional en el Agamenón - pp. 65-74- y otro al conflicto de códigos éticos en el Hipólito - pp. 75-88-, realizados desde un punto de vista metodológico y conceptual del que divergimos por completo.

3 Se utilizan los términos $\gamma \varepsilon \hat{\varepsilon} \omega \nu$, đuvip $v \varepsilon \propto v l \propto \varsigma$ para nominar las tres edades: vejez, edad madura y primera juventud, que se encuentran en la tragedia entrando en oposiciones formales. 
5 Yocasta-Polinices, Etéocles

Anfitrión-Mégara

7 Coro, Anfitrión-Lico, Mégara

8 Anfitrión-Heracles

9 Peleo-Andrómaca

10 Peleo-Menelao

11 Ifis - Evadne

12 Coro-Edipo

13 Edipo-Teseo

14 Hécuba-Agamenón

15 Hécuba-Odiseo

16 Etra-Teseo

17 Servidor - Agamenón

18 Servidor-Clitemestra

19 Servidor-Creúsa

2) $\gamma \varepsilon \rho \omega v / v \varepsilon \alpha v i \alpha \varsigma$

1 Edipo-Antígona, Ismene

2 Pedagogo-Antígona

3 Yolao-Macaria

4 Servidor-Electra, Orestes

5 Tindareo-Orestes

3) \&vip / ve๔vlas

1 Creonte-Hemón

2 Deyanira-Yola

3 Odiseo-Neoptólemo

4 Agamenón-Ifigenia, Aquiles

6 Heracles -Hilo

7 Filoctetes - Neoptólemo

8 Creonte-Antígona

9 Andrómaca-Hermíone

10 Clitemestra-Electra

11 Creúsa-Ión

12 Juto-Ión

4) $\gamma \varepsilon \rho \omega v / \alpha v \eta \dot{\rho} / v \varepsilon \propto v l \propto \varsigma$

1 Edipo-Polinices - Antígona

2 Hécuba-Odiseo-Políxena

3 Tiresias - Creonte - Meneceo
Fenicias 261-637

Heracles loco 60-106 y 451-522

Heracles loco 140-347

Heracles loco 585-636; 1088 ss.

Andrómaca 547-576 y 747-765

Andrómaca 577-746

Suplicantes 1034-1071

Edipo rey 650-667

Edipo en Colono 551-668

Hécuba $726-845$

Hécuba 218-250

Suplicantes 286-364

Ifigenia en Aulide 111-163

Ifigenia en Aulide 866-895

Ión 725-1047

Edipo en Colono 1-35; 81-116 y 1096-1118

Fenicias 88-201

Heraclidas $474-607$

Electra $487-575$ y $576-698$

Orestes 491-633

Antigona $631-769$

Traquinias 141-177; 229-496

Filoctetes 1-134 y 1222-1262

Ifigenia en Autide 631-676; 1211-1275; 801-

854; 896-1035 y 1276-1509

Traquinias 1115-1274

Filoctetes 219-390; 403-541; 629-675; $730-$

826 ; $865-973$ y $1263-1408$

Antígona $441-525$ y $883-928$

Andrómaca 147-272

Electra 999-1147

Ión 238-380

Ión 510-675

Edipo en Colono 1254-1555

Hécuba 251-379; 382-443

Fenicias 834-1019

No siempre a una oposición formal responde invariablemente un contenido en el que la noción de edad sea relevante. Esto quiere decir 
que no en todas las estructuras formales, arriba reseñadas, es pertinente la noción de edad. Aquí tan sólo interesan aquellas en que dicha noción es pertinente.

Ante todo hacer algunas precisiones acerca de aquellas oposiciones de forma a las que no responde una de contenido; en otras palabras, donde se da ya una neutralización de la noción de edad, ya una irrelevancia de dicha noción.

La neutralización de la marca de edad viene dada porque otra noción es la única marcada. Es éste el caso en que el carácter atemporal del personaje literario anula la linealidad existencial de la persona.

No siempre es fácil establecer el corte, ni siquiera con la ayuda del léxico y de los rasgos extralexicales, aunque ambos elementos sean los que sirven de pauta para establecerlo. Quedan zonas de transición en que la persona inserta en la linealidad del tiempo vital y el personaje literario no están suficientemente delimitados; o sea, donde no se produce propiamente una neutralización de la noción de edad en el mismo sentido que la anterior, sino una gradación entre varias nociones pertinentes, de la que resulta que la noción de edad es proporcionalmente irrelevante en función de la relevancia de otras nociones. Es éste, entre otros, el caso en que dos personajes se oponen primordialmente en la noción padre / hijo, benefactor / suplicante, autoridad religiosa / autoridad humana, servidor fiel a la familia / señor.

De este aspecto marginal al núcleo del presente estudio es mi intención ocuparme en otro lugar. Aquí me voy a ocupar de aquellas estructuras formales en que la noción de edad es con toda claridad pertinente y lo es en mayor gradación que cualquier otra.

Son las siguientes:

Estructuras en que alternan $\gamma \hat{\varepsilon} \rho \omega \nu / \not \alpha v \eta \dot{\rho} \rho:$ la 1,3 y 5.

Estructuras en que alternan $\gamma \hat{\varepsilon} \rho \omega \nu / v \varepsilon \alpha v$ los: la 1 .

Estructuras en que alternan $\alpha v \eta \dot{\rho} / v \varepsilon \propto v l \propto \varsigma$ : la 1, 2, 3 у 4.

Nuestro objetivo en la parte que sigue se cifra en intentar delimitar los rasgos distintivos de cada período de la vida del hombre, tanto si vienen marcados por procedimientos lexicales como si no es así.

En adelante, pues, seguimos nuestro estudio en dos travesías: una primera, que ha constituido nuestro punto de partida - la parte primera de este estudio- marcada por el léxico; y otra segunda travesía en la que las marcas pertinentes de cada período de la vida del hombre se encuentran en el plano del contenido. Con esta segunda travesía me refiero al hecho de que en cada antagonista hay una actitud ante una 
situación dada, o sea, ante el dilema de la tragedia en cuestión, que se puede patentizar en acción y palabras o bien sólo en palabras; y una actitud ante las posiciones de su antagonista, que se puede patentizar también por uno u otro de los procedimientos dichos.

b) Estructuras formales $\gamma \varepsilon \hat{\varepsilon} \rho \omega / \not \alpha v \eta ́ p$

1) Coro/Creonte

El coro de Antigona está constituido por ancianos de Tebas. En el primer episodio hay dos estructuras dialógicas ${ }^{4}$ entre el jefe del coro y Creonte, interrumpidas por la llegada de un guardián anunciando que alguien ha intentado dar sepultura al cadáver de Polinices.

La tercera estructura dialógica ${ }^{5}$ entre el corifeo y Creonte, perteneciente al quinto episodio, sigue al enfrentamiento entre Tiresias y éste en lo tocante a la condena a muerte de la joven Antígona.

La cuarta estructura pertenece al éxodo ${ }^{6}$ y se inserta tras el trágico desenlace de la muerte de Antígona y Hemón, interrumpida por la entrada en escena de un mensajero que anuncia el suicidio de la esposa de Creonte.

En las fórmulas de interpelación de estas estructuras no se encuentran términos pertenecientes al campo semántico de la edad para ninguno de los dos oponentes: Creonte interpela primero al coro con el término ${ }^{\natural} \nu \delta \rho \varepsilon \varsigma^{7}$, que carece de connotaciones contextuales de edad; luego no utiliza ninguna fórmula de interpelación para dirigirse al cori-

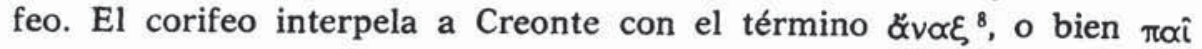

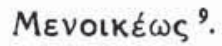

En el plano referencial se encuentra el término $\gamma \hat{\varepsilon} \rho \omega \nu{ }^{10}$, empleado por Creonte para referirse al corifeo. En cambio, tampoco en este otro plano hay término alguno perteneciente al léxico de la edad aplicado a Creonte. Estamos, pues, ante una estructura sólo parcialmente marcada por el léxico.

Son rasgos extralexicales y de contexto amplio los que nos hacen saber que Creonte es un hombre en la edad madura de la vida: es esposo, padre y tío de dos jóvenes que aún no han contraído matrimonio; es además un hombre que tiene la edad adecuada, para un grie-

\footnotetext{
4 S. Ant. $155-222$ y $278-314$.

5 S. Ant. 1091-1114.

6 S. Ant. 1261-1352.

7 S. Ant. 163.

8 S. Ant. 278,1091 y 1103.

9 S. Ant. 1098.

10 S. Ant. 281.
} 
go del siglo $v$ como es Sófocles, para ser dirigente del Estado. Esta es una primera información que sirve de punto de partida.

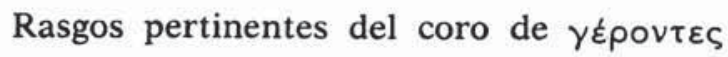

Tienen una primera actitud expectante y llena de reservas ante el

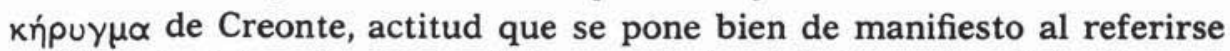
a él llamándolo "el reciente dirigente de la ciudad en virtud de circunstancias nuevas»" Una vez que Creonte ha expresado al coro el conte-

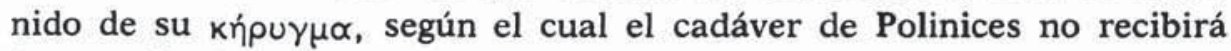
honras fúnebres, el coro adopta ya una actitud y emite un primer y velado juicio de valor: no muestra respeto a la legitimidad incuestionable del decreto de Creonte $\multimap \varepsilon \hat{\varepsilon} \beta \propto \varsigma-$ ni lealtad para con él - $\varepsilon \mu \pi \varepsilon$ -

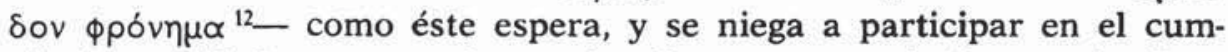
plimiento del decreto, con la evasiva de que otro más joven sobrelleve tal carga ${ }^{13}$. El coro ni apoya ni participa en una decisión que no ha sido la de la ciudad, emitida en votación; no es un $\psi \dot{\eta} \phi \iota \sigma \mu \alpha$, sino una

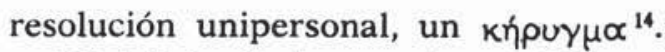

El juicio de los ancianos del coro se pone de manifiesto con la

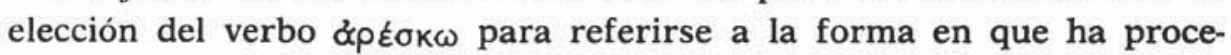
dido Creonte, juicio que se completa al poner énfasis en la afirmación de que él puede valerse de todo tipo de leyes, tanto respecto a los muertos como a los vivos ${ }^{15}$.

Cuando un guardián da noticias de que alguien ha intentado sepultar el cuerpo de Polinices, el anciano jefe de coro manifiesta su creencia de que es querido por los dioses que no se lleve a efecto la resolución de Creonte ${ }^{16}$. Después del enfrentamiento entre éste y Tiresias, el coro ya no aparece como antagonista de un hombre seguro de la validez de su criterio, sino de un ser humano perplejo y turbado en lo más hondo de su identidad.

Tanto su actitud como sus palabras están marcadas por el «buen consejo» $-\varepsilon \dot{u} \beta o u \lambda l \alpha^{17}-$. Ante la conducta del hombre hundido por la marcha de los acontecimientos, que no ha podido evitar ya, el coro

11 S. Ant. 156-57.

12 S. Ant. 166 y 169.

13 S. Ant. 216.

14 Cf. A. Díaz Tejera, La Antigona de Sofocles: su mensaje humanista, Sevilla 1982 , p. 39 , sobre el carácter de «pregón en una situación de emergencia del decreto de Creontex.

15 S. Ant. 211-14.

16 S. Ant. 278-79.

17 S. Ant. 1095 ss. 
tiene un solo juicio $-\alpha \mu \alpha p \tau i \alpha^{18}-$. Es «conocimiento del justo valor de cada cosa», aconocimiento del relativo valor intrínseco de todo cri-

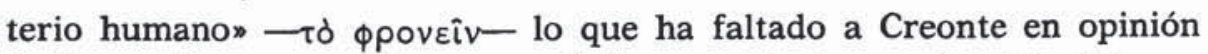
de los ancianos; aquella característica que, junto con la $\varepsilon \dot{\jmath} \beta o u \lambda\{\alpha$, es su patrimonio, pues sólo se llega a adquirir en la vejez ${ }^{19}$ : $\phi \rho \delta$ vnoıs y $\varepsilon \dot{\beta} \beta 0 u \lambda l \alpha$ son los rasgos significativos del coro de ancianos de Antígona. Ambos rasgos se manifiestan: en su negativa a colaborar con aquella decisión que ni es reflejo de la voluntad unánime de la polis, ni está de acuerdo con las leyes no escritas, de origen divino; en su posterior

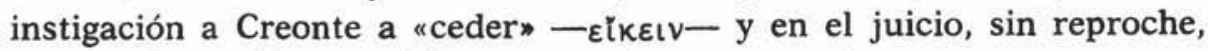
del hombre caído que define su conducta como $\alpha \mu \alpha \rho \tau(\alpha$.

\section{Rasgos pertinentes de Creonte}

En las cuatro estructuras dialógicas en que se contraponen $\gamma \hat{\varepsilon} \rho \omega \nu$ / ¿́rvía se desvelan en un paulatino desarrollo facetas que constituyen los rasgos distintivos del hombre en la madurez de su vida.

En las dos primeras estructuras, la moderada reprobación del coro de ancianos contrasta con la irrenunciable decisión de Creonte: el hombre que cuenta ya con un pasado en el haber de su vida, que lo ha vinculado a la familia de Layo, y lo ha situado al timón de la vida pública en un momento de crisis. Historia de la persona que se ha ido elaborando a través de elecciones individuales dentro del ámbito de unas circunstancias exteriores. Es, pues, un hombre comprometido consu pasado, que ha llegado a integrar su propia identidad, con un bagaje de convicciones y de comportamientos porellas dictados; comprometido con la existencia de una imagen ante los demás, y cuya vida se sigue desarrollando en el ámbito de la acción, de las elecciones por tanto.

El decreto de Creonte y la seguridad de proceder rectamente ${ }^{20}$ no es otra cosa que el resultado del compromiso del individuo con su propio ser, labrado de convicciones adquiridas y de comportamientos por ellas dictados, que constituyen su patrimonio irrenunciable; y del compromiso con su "parecer», o sea, con su imagen ante los otros hombres.

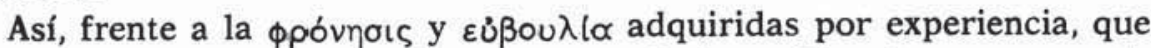
caracterizan al anciano coro, al margen de la acción, Creonte pasa de

18 S. Ant. 1260.

19 S. Ant. $1350-53$.

20 S. Ant. $164-210$ y $280-314$. 
la confianza en su propio criterio al apasionamiento - $\delta \rho \gamma \eta ́-$ en defenderlo ante la más mínima sugerencia de posible error ${ }^{21}$; de ahí, a la

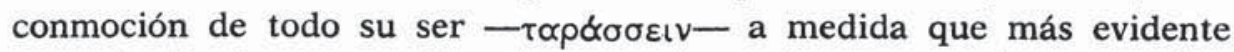
se va haciendo el error ${ }^{22}$, a la renuncia $-\varepsilon$ โ $\varepsilon \varepsilon เ v-$ y a la aceptación, por fin, de su $\alpha \mu \alpha p \tau i \alpha^{23}$.

\section{2) Feres/Admeto}

El cuarto episodio de Alcestis lo ocupa casi en su totalidad el enfrentamiento entre Feres y su hijo Admeto, que se inicia con dos resis alternadas, para continuar en composición dialógica ${ }^{24}$.

Feres interpela a Admeto con los términos $\tau \dot{\varepsilon} \kappa \nu \circ \nu$ y $\pi \propto \hat{\imath}^{25}$, en las nociones 'hijo' / 'padre', colindantes con las de edad, al comienzo de la estructura, para no emplear ningún término de interpelación en la parte dialógica, en la que la tensión entre ambos hombres va en aumento.

Admeto, al que la sola presencia de su padre irrita, no emplea ningún término de interpelación para dirigirse a quien estima que no ha procedido en la forma adecuada a un padre para con su hijo.

El corifeo interpela a Admeto con el término $\pi \propto \hat{\imath}^{26}$, en su uso afectivo, neutro en cuanto a la noción de edad, en su breve intervención entre la resis de Admeto y la de Feres; y a Feres con el término $\pi \rho \varepsilon \sigma \beta u \varsigma$, en su intervención entre la resis de éste y el comienzo del diálogo ${ }^{27}$.

En el plano referencial, está presente la oposición $\gamma \hat{\varepsilon} \rho \omega \nu / \nu \varepsilon_{o}{ }^{28}$ para aludir a Feres y a Admeto respectivamente.

Es ésta, por tanto, una estructura marcada por el léxico en sus dos términos.

La restante información acerca de la edad de Admeto viene dada por el contexto amplio. Nos hace saber que es esposo y padre de hijos adolescentes; es, pues, Admeto un hombre en la edad madura de su vida, en el cenit de su juventud.

En esta estructura formal no oponen al $\gamma \xi \rho \omega \nu$ y al $\alpha v \eta p$ comportamientos distintos ante una misma situación, sino que la nota dominante

21 S. Ant. 280-81.

22 S. Ant. 1095-97.

23 S. Ant. 1262.

24 E. Alc. 611-742.

25 E. Alc. 614 y 675.

26 E. Alc. 674.

27 E. Alc. 707.

28 E. Alc. 635. 
en uno y otro es el egoísmo, rasgo que opone a ambos a Alcestis, la heroina que se sacrifica a sí misma en beneficio del prójimo.

Son puntos de vista que revelan sus vivencias acerca del valor intrínseco de la existencia, los que enfrentan sin posibilidad de aceptación mutua a los dos hombres y a los dos períodos de la vida que ellos representan.

\section{Rasgo pertinente de Feres}

Hay una idea que aparece recurrente a lo largo de toda la argumentación de Feres. Se apunta por primera vez en su resis y se recoge más adelante en puntos escalonados de la estructura dialógica. La idea es la de que la existencia es la más preciada posesión del hombretantosi setrata de un joven comode un anciano.

Esta idea expuesta con realismo y hasta cinismo es la que constituye el rasgo pertinente del anciano Feres en la oposición Feres / Admeto.

$\mathrm{La}$ esboza por primera vez en la resis, al sostener que la vida es tan amable para él como para su hijo ${ }^{29}$. En la estructura dialógica, al sostener que el amor a la propia vida es común a todos los hombres sin distinción de edad ${ }^{30}$, en razón de que sólo les ha sido dado vivir

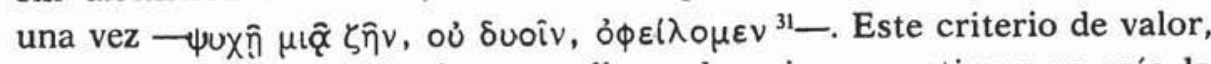
al superponerse a cualquier otro, lleva al anciano a estimar en más la existencia, aunque ella sea breve, a la "buena fama» una vez muerto

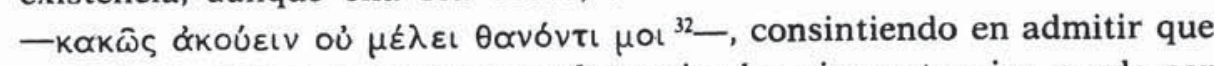
preferir la vida a la muerte en determinadas circunstancias puede ser

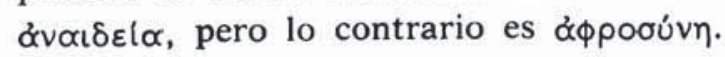

\section{Rasgos pertinentes de Admeto}

Admeto igual que Feres se caracteriza por el egoísmo, pero a diferencia de éste, mide en dos parámetros distintos el valor intrínseco de la existencia, pues valora su vida como algo intrínsecamente diferente a la del anciano, en razón de su juventud, mientras no concede valor intrínseco a la existencia, ya breve, de la vejez.

29 E. Alc. $691-93$.

30 E. Alc. $703-705$ y 722 .

31 E. Alc. 712.

32 E. Alc. 726. 
Si bien la valoración de su propia existencia lo lleva a coincidir con su antagonista en anteponer ésta a cualquier sentimiento humanitario y a coincidir asimismo en la ćauxía ante la muerte, el considerar que la vida es el supremo valor cuando de la de una persona joven se trata, pero no así cuando se trata de la de una anciana, lo sitúa en el punto de divergencia con Feres. Esta idea es la recurrente en toda la exposición de Admeto.

Se encuentra primero en su resis, cuando estima una inconsecuencia que su padre pretenda tomar parte en los ritos funerarios en honor a Alcestis, no habiendo estado al lado de su hijo a la hora de las decisiones irrevocables, y habiendo consentido que una persona joven mu-

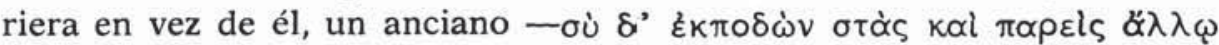

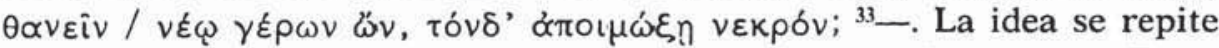
unos versos más adelante, en la misma resis, cuando acusa a Feres de $\alpha \dot{\psi} \psi x \downarrow l \propto$ por haber preferido salvar su vida a la de su hijo ${ }^{34}$. La noción de la brevedad de la vida del anciano Feres se precisa poco después

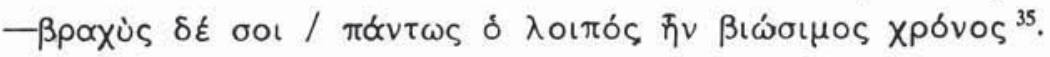

La valoración nula que Admeto hace del último período de la vida del hombre encuentra su más firme punto de apoyo en la constatación de que la dicha acompañó la existencia de su antagonista durante la $\eta \beta \eta$, única etapa valorable a su juicio. En criterio del hijo, cuanto el hombre puede esperar de la existencia ya está cumplido, por lo que emplea el perfecto $-\pi \dot{\varepsilon} \pi \circ v \theta \propto \varsigma^{36}$.

La idea dominante hace su aparición de nuevo en la estructura dialógica, donde el joven Admeto pregunta "si acaso es igual que muera

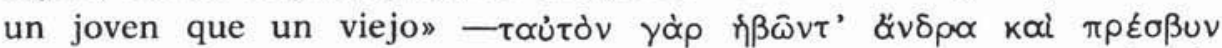
$\theta \propto v \varepsilon i{ }^{37}$ - Con ello pone de manifiesto el valor relativo que a su juicio tiene la existencia humana, siendo la juventud la que le confiere un valor absoluto.

Este es el rasgo pertinente de Admeto en su oposición con Feres, y a dicho rasgo es al que se le aplica el nombre de ußpis y al medio de expresión que le da forma el de "palabras adecuadas a un $v \varepsilon \alpha v l \alpha \varsigma$ ", no propias de un verdadero đ̌ $v \eta \rho^{38}$.

33 E. Alc. $634-35$.

34 E. Alc. $642-45$

35 E. Alc. $649-50$.

36 E. Alc. 634.

37 E. Alc. 711.

38 E. Alc. $679-80$. 
3) Yocasta/Polinices, Etéocles

El primer episodio de Las Fenicias está constituido por una larga escena en la que intervienen la anciana Yocasta, que intenta una conciliación entre sus oponentes, sus dos hijos: Polinices y Etéocles, enfrentados entre sí por la ambición de ostentar el poder en Tebas ${ }^{39}$.

La estructura literaria se inicia con un solo lírico de Yocasta al ver de nuevo, tras tiempo y avatares, a su hijo Polinices ${ }^{40}$, al que responde una resis de éste ${ }^{41}$, seguida de una estructura dialógica entre ambos ${ }^{42}$. Después de la breve intervención del corifeo, que anuncia la llegada de Etéocles, y de unas breves palabras con que éste se dirige a su madre, se siguen cuatro resis: Yocasta-Polinices - Etéocles - Yocasta, separadas por breves intervenciones del corifeo ${ }^{43}$.

En esta estructura formal, la noción basada en la oposición 'madre' / 'hijo' es noción pertinente junto con la de la edad; de ahí los términos de interpelación que se encuentran.

Yocasta es interpelada por Polinices con el término $\mu \eta \hat{\tau} \varepsilon \rho^{44}$ y por Etéocles con el mismo término $\mu \eta \hat{\tau} \varepsilon \rho^{45}$.

Polinices es interpelado por su madre con el término $\tau \varepsilon \kappa \kappa \nu v^{46} \mathrm{y}$ por Etéocles con los términos $\tau$ tźkvov y $\pi \propto{ }^{4}{ }^{47}$.

En el plano referencial, Yocasta emplea el término $\gamma \tilde{p} p \propto \varsigma$, opuesto a $v$ Éos para referirse a su edad frente a la de sus hijos ${ }^{48}$.

Se trata, pues, de una estructura formal marcada por el léxico en sus dos términos.

\section{Rasgos pertinentes de Yocasta}

Los primeros rasgos que aparecen son físicos: La de bilidad de la edad se manifiesta en el paso vacilante y el caminar que no levanta los pies del suelo ${ }^{49}$; el cabello blanco que dice la anciana que

\footnotetext{
39 E. $P h .261-637$.

40 E. $P h .301-54$.

41 E. $P h .357-78$.

42 E. $P h .379-442$.

43 E. $P h .452-586$.

44 E. Ph. 357, 374, 386, 436 у 494.

45 E. $P h .446,503,507$ y 516 .

46 E. $P$ h. 304, 324, 412, 576, 582.

47 E. $P h .528,532$ y 535.

48 E. $P h .529-30$.

49 E. Ph. 301-303.
} 
se ha cortado en señal de dolor por la ausencia de su hijo $-\lambda \varepsilon \cup \kappa \delta$ $\chi \rho \circ \alpha \ldots \kappa \delta \mu \alpha v^{50}$.

Los otros rasgos son de índole espiritual. Es una idea central la a ñ or a nza - $-\pi$ ó os - que acompaña la existencia de la anciana por "la ausencia presente en ella» del hijo amado, expresada al comienzo del solo lírico: "añorado" - $\pi 0 \theta \varepsilon เ v o ́ \varsigma-$ es Polinices ${ }^{51}$. La ausencia ha creado en el ser de la anciana un sentimiento de soledad, de vacío que ella proyecta a la casa - Epquov ${ }^{52}$ - y que la ha llevado a cambiar sus comportamientos, por lo que descuida su persona para manifestar públicamente su $\pi b \theta$ os. El mismo sentimiento impulsa a la madre a inquirir expectante de su hijo todo cuanto le ha ocurrido en en el tiempo en que ha estado ausente y que ella sólo ha llegado a saber por referencias.

El sentimiento de $\pi \delta ́ \theta \circ \varsigma$ aparece consustancialmente vinculado a la ancianidad, motivado por la falta de la presencia física de los jóvenes amados, de los hijos amados; como aparece en otros lugares y contextos vinculado al amante por la ausencia del amado.

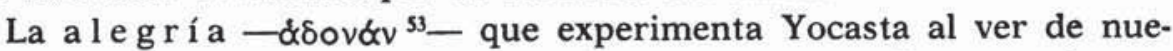
vo a su hijo es otro rasgo marcado. Un gozo - $\tau \hat{\varepsilon} \rho \psi r v^{54}-$ que, de una parte la deja muda e inerte: no sabe qué cosa pueda decir, ni la palabra, ni el gesto pueden expresar su alegría; y de otra parte, la impulsa a pedir a su hijo que le prodigue todas las caricias al tiempo ${ }^{55}$.

Ella misma reconoce que su gozo sólo puede manifestarlo dando vueltas en torno a Polinices, como en una danza. La lentitud y vacilación en el caminar propias de la edad contrastan con el deseo de bailar alrededor de su hijo en señal de regocijo.

Otro rasgo de Yocasta, frente a sus hijos, es la experiencia $-\varepsilon \mu \pi \varepsilon i \rho l \alpha-$ patrimonio de la vejez y un bien inherente a ella. Es la $\varepsilon \mu \pi \varepsilon i p l \alpha$ de la última etapa de la vida del hombre la que hace que sea patrimonio de esta edad, frente a la $\ddot{\eta} \beta \eta$, la $\sigma 0 \phi l \alpha^{56}$. La $\sigma \circ \phi i \alpha$ que posee Yocasta se manifiesta en el "buen consejo» dado a sus hijos jóvenes. Ella dice que quiere darles "un consejo acertado» - $00 \phi \delta v^{57}$ que se opone a la "ignorancia de la justa medida de cada cosa» - $\alpha \mu \alpha-$

50 E. $P h, 322-23$.

51 E. $P h .320-21$.

52 E. $P h .318$.

53 E. $\mathrm{Ph} .314$.

54 E. $P h .316$

55 E. $P$ h. $306-309$.

56 E. $P h .528-30$.

57 E. $\mathrm{Ph} .460$. 
$\theta / \alpha$ - de Etéocles y de Polinices ${ }^{58}$. El "consejo acertado" que procede de la $\sigma 0 \phi i \alpha$ de Yocasta, adquirida gracias a su $\varepsilon \dot{\mu} \mu \varepsilon\llcorner\rho i \alpha$, tiene una doble proyección: es un consejo de serenidad para afrontar las diferencias que enfrentan a los hermanos, que se opone al "apasionamiento» - b́pŕ- de éstos; y un consejo de moderación en la vida, que se opone a la "ambición" -

Serenidad en las palabras - $\beta p \alpha \delta \varepsilon i s ~ \mu u ́ \theta o t-$ pide Yocasta a Etéocles, frente a su vehemencia - $\tau$ ò $\tau \propto \chi^{50}{ }^{59}-$. Serenidad en la actitud aconseja a los dos hermanos que rehúsan encontrar sus miradas. Serenidad en el ánimo pide a ambos, al instarlos a afrontar sólo el presente, dando paso al olvido de los daños del pasado ${ }^{60}$.

Rasgos pertinentes de Etéocles y Polinices

A pesar de las diferencias existentes entre Polinices y Etéocles, los dos hombres tienen unos rasgos distintivos comunes que los oponen a aquellos que caracterizan a la anciana Yocasta.

Un pas a do integrado por elecciones de comportamiento los ha situado en la posición inconciliable que constituye su presente.

Su vida se desarrolla en el campo de la a c ción.

Ambos proceden movidos por la a mbición $-\phi i \lambda o \tau i \mu i \alpha-y$ tanto la actitud de los dos hermanos como las palabras de Etéocles están dictadas por el apasionamiento-bpyn.

c) Estructuras formales $\gamma \varepsilon \hat{\varepsilon} \rho \omega / v \varepsilon \alpha \nu\{\alpha \varsigma$

1) Edipo/Antígona, Ismena

El prólogo de Edipo en Colono se inicia con una estructura dialógica entre el anciano Edipo y la joven Antígona, peregrinos que se aproximan a Atenas. La estructura dialógica entre Edipo y Antígona se ve interrumpida por otra entre un habitante de Atenas y Edipo, para continuarse luego hasta el final del prólogo, marcado por la entrada en escena del coro ${ }^{61}$.

La párodos consiste en un diálogo lírico entre Edipo, el coro y Antígona ${ }^{62}$.
58 E. $P h .584-85$.
59 E. $P h .452-53$
60 E. $P h .461-64$.
61 S. EC 1-116.
62 S. EC 117-253. 
En la parte primera del primer episodio hay una estructura dialogica entre Edipo e Ismena, su otra hija, que va a la búsqueda de su padre para darle noticias del conflicto que enfrenta a sus hermanos varones y de los recientes oráculos concernientes a la suerte del viejo Edipo ${ }^{63}$.

En el tercer episodio hay otra breve estructura dialógica entre Edipo y Antígona, con la presencia muda de Ismena, una vez que Teseo ha hecho posible que el padre recupere a sus hijas ${ }^{64}$.

En esta estructura de forma que ahora nos ocupa, además de la noción de edad, es también pertinente la noción expresada por la oposición $\pi \propto \tau \eta \dot{\rho} / \pi \propto i s$, colateral a la de la edad. Este hecho queda reflejado en los términos de interpelación.

Edipo es interpelado por sus hijas con el término $\pi \alpha \tau \eta \rho^{65}$, y por el coro con los términos $\pi \rho \varepsilon \sigma \beta u \varsigma^{66}$ y $\gamma \varepsilon \hat{\varepsilon} \omega \nu^{67}$.

Antígona e Ismena son interpeladas por su padre con los términos

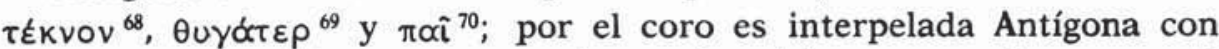
el término коúpa ${ }^{71}$ que, como veíamos detenidamente en la parte primera de este trabajo, se refiere exclusivamente a la primera etapa de la juventud.

Se trata, pues, de una estructura bien caracterizada por el léxico relativo al campo semántico de la edad en sus dos términos.

\section{Rasgos pertinentes de Edipo}

Hay unas características peculiares de índole física que se conjugan con otras de índole espiritual.

La debilidad física y la enfermedad llevan consigo la confiada dependencia de la persona joven y en plenitud de facultades.

Son manifestaciones de la debilidad física: el cansancio ${ }^{72}$ por haber recorrido un largo camino (así, el anciano Edipo necesita encontrar un acomodo en el que descansar); el t e mor a dar un paso en

63 S. EC $324-460$.

64 S. EC $1099-1138$.

65 S. EC 16, 82, 327, 332, 361, 387, 407, etc.

66 S. EC 124, 143.

67 S. EC 177, 209.

68 S. $E C 1,9,81,27,213,216,327,332,342,353,388,410,412$.

69 S. EC 170, 225, 398.

70 S. EC $188,329$.

71 S. EC 180, 188, 322.

72 S. EC $19-20$. 
falso en su primer contacto con un entorno desconocido que, por lo demás, no ve (así, cuando Antígona encuentra un lugar en que descanse el anciano, él no se atreve a dirigirse solo hasta él). El mismo temor a no poner el pie en lugar seguro, a hacer un movimiento en falso para sentarse donde el coro le indica, se pone de manifiesto en la primera parte del diálogo lírico perteneciente a la párodos: "cógeme», pide a Antígona, "llévame tú, hija» ${ }^{73}$.

La confiada dependencia física que tiene el anciano en la joven la expresa por medio del empleo del verbo $\phi \cup \lambda \measuredangle \sigma o \sigma \omega ; y$, en igual sentido, Edipo considera a su hija Ismena su "guardiana»- $-\dot{ } \lambda \propto \xi^{74}$.

Es el léxico el que va marcando la idea de debilidad, temor producido por ella, sentimiento de dependencia del joven, confianza en su

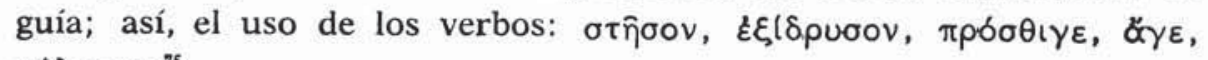
$\phi u ́ \lambda \propto \sigma \sigma \varepsilon{ }^{75}$.

Las restantes características son exclusivamente de índole espiritual:

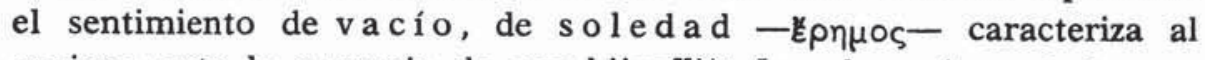
anciano ante la ausencia de sus hijas ${ }^{75}$ bis. La a legría ante la presencia inesperada de las jóvenes. El sentimiento de alegría está bien marcado por el léxico, además de por otros procedimientos como el de la interrogación breve y reiterativa. El léxico expresa nociones de «presencia física", de "cercanía», de "contacto amoroso». Tanto ante la imprevista llegada de Ismena como cuando Teseo le devuelve a las dos muchachas, el regocijo del anciano se manifiesta en sus preguntas: "¿han llegado?», "¿están cerca?»; en sus ruegos: «acercaos», «abrazad-

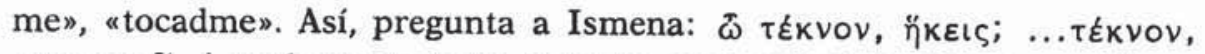
$\pi \dot{\varepsilon} \phi \eta v \propto \varsigma^{76}$. A ambas pregunta, una vez que, contra su esperanza, Teseo

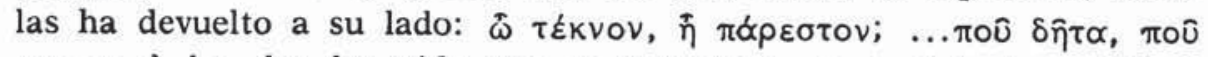

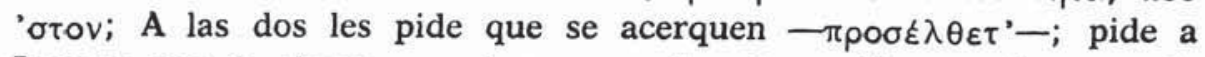

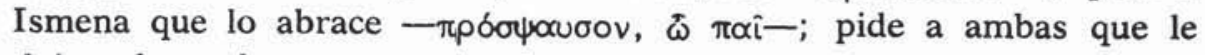
dejen abrazarlas - $\sigma \hat{\omega} \mu \alpha \beta \alpha \sigma \tau \delta \sigma \sigma a r$ $\delta \delta \tau \varepsilon-;$ que se cobijen las dos bajo

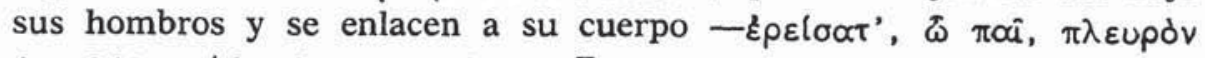

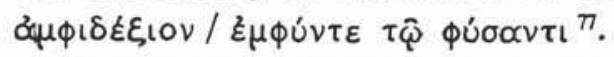

Otro rasgo de Edipo, que ha ido adquiriendo con el sufrimiento y el paso del tiempo, es la ductilidad de la resignación-otép$\gamma \varepsilon v^{78}$.

73 S. EC $173,188$.

74 S. EC 21 y 355.

75 S. $E C 11,173,188$ y 21 respectivamente.

75 bis S. EC 1114.

76 S. EC 327 y 328.

77 S. $E C$ 1102, 1107, 1104, 329, 1105 y 1112-13.

78 S. EC 7. 
Es característica de Edipo suscitar respeto. Es ésta la actitud que despierta en el coro, en el rey de Atenas, en sus hijos.

El último rasgo que caracteriza al anciano es su certeza de que ya no habrá para él un futuro con rumbo diferente al del pasado: cuando Antígona le hace saber que su persona, abatida en la juventud, ahora es necesaria para la salvación de su pueblo, Edipo sabe que la vida del hombre se modela en su conformación definitiva a lo largo de la madurez y es inútil creer que

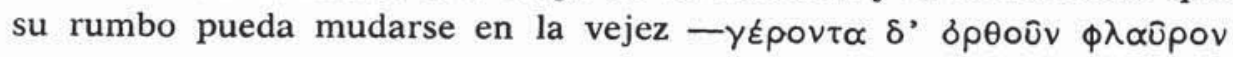

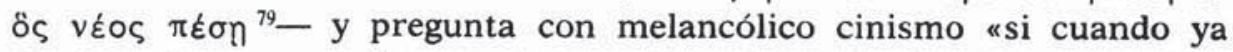
no es nada, a su edad, va a ser considerado un hombre».

\section{Rasgos pertinentes de Antígona e Ismena}

Antígona e Ismena son mujeres que se encuentran en la primera etapa de su juventud, y ambas están bien caracterizadas por rasgos diferenciales que les son propios.

Uno de dichos rasgos lo constituye el contraste entre su fragilidad y su dureza, tanto en el plano de lo físico como en el de lo moral. Fragilidad y dureza se ponen de relieve en los conceptos opuestos con que Edipo se refiere a ellas: son $\pi \propto p \theta \varepsilon v o \iota$ y en contraste actúan como si fueran ópoeves, al contrario que sus hermanos varones ${ }^{80}$. De este modo, Antígona apenas dejó de ser niña $-v \varepsilon \alpha-$

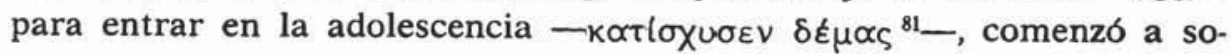
portar una vida dura: andar errante sin hogar $-\pi \lambda \alpha \nu \omega \mu \varepsilon v \eta^{82}$, sin

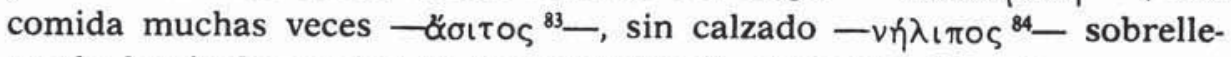
vando las inclemencias de la naturaleza ${ }^{85}$, sirviendo de guía a un anciano $-\gamma \varepsilon \rho \circ \nu_{\tau} \propto \gamma \omega \gamma \varepsilon \hat{\imath}{ }^{86}$.

También se nos dice que Ismena desde la adolescencia ha llevado una vida de dureza: ella se convirtió voluntariamente en la «fiel guardiana” de su padre desde que fue desterrado ha velado por él, viéndose obligada para ello a ocultarse de sus conciudadanos y familiares.
79 S. EC 395.
80 S. EC $342-60$.
81 S. EC $345-46$.
82 S. EC 347.
83 S. EC 349.
84 S. EC 349.
85 S. EC 350.
86 S. EC 348.

LI, $2 .^{\circ}-4$ 
La otra característica de las dos jóvenes es la capacidad de sacrificio, o sea, la entrega gratuita de sus personas por sentido de la propia responsabilidad y por amor. Este rasgo pertinente de ambas jóvenes queda plasmado en las palabras con que Ismena manifiesta que "no está bien ni siquiera guardar memoria del penoso esfuerzo que han realizado» ${ }^{87}$. La entrega gratuita de sí mismo, que es marca distintiva de las dos jóvenes, se proyecta en los $\mathrm{cuidados}$ materiales que prodigan al anciano en su indefensión y soledad; y en los cuidados de tipo moral que le prodigan asimismo: así la $\pi \rho \circ \mu \eta \theta / \alpha^{88}$ es lo que mueve a Ismena a reunirse con su padre para llevarle noticias que le beneficia conocer antes de que los acontecimientos se precipiten; ánimos le da Antígona al anciano para que confíe en el coro de atenienses y vela por su padre, dirigiendo al coro

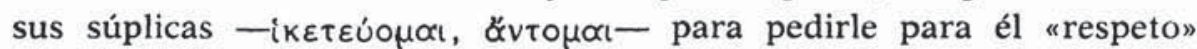

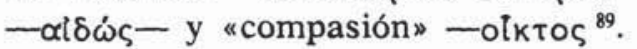

d) Estructuras formales $\alpha v \eta \rho / v \varepsilon \alpha v\{\propto s$

1) Creonte/Hemón

Casi todo el tercer episodio de Antígona lo ocupa el enfrentamiento entre Creonte y su hijo Hemón. Este último hace su aparición en escena después de que Creonte haya hecho prisionera y condenado a muerte a Antígona por haber dado sepultura al cadáver de Polinices, violando el decreto promulgado por él. Hemón intenta interceder por Antígona ante Creonte en un principio, para continuar la escena con un violento enfrentamiento entre padre e hijo ${ }^{90}$.

La estructura literaria está integrada por dos resis sucesivas de Creonte y Hemón respectivamente, separadas por una breve intervención del corifeo ${ }^{91}$; seguidas, tras otra breve intervención del corifeo, de una composición dialógica esticomítica en su casi totalidad ${ }^{92}$.

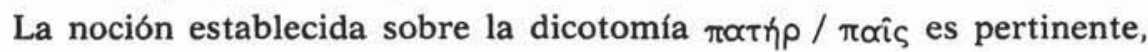
sumándose a la establecida sobre la noción de edad óvin / veavlas; de ahí los términos de interpelación que se emplean.

\footnotetext{
87 S. EC 508-9.

88 S. EC 332.

89 S. EC 237-54.

90 S. Ant. 631-765.

91 S. Ant. $639-80$ y $683-723$.

92 S. Ant. $726-65$.
} 


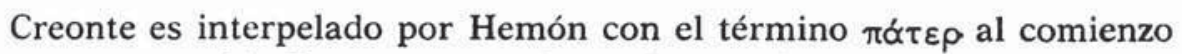
de su conversación ${ }^{93}$, para no emplear ningún término de interpelación desde el momento en que surge la tensión entre los dos hombres.

Creonte empieza dirigiéndose a Hemón con el término $\pi \propto \hat{\imath}^{94}$, para no utilizar ningún término de interpelación, igual que su hijo, cuando se inicia la controversia entre ambos.

En el plano relacional, Hemón es el que está caracterizado por el término $v \varepsilon \varsigma^{95}$, que se encuentra en su forma comparativa cuando de lo que se trata es de oponer la edad del hijo a la menor juventud del padre.

En la diferencia de edad entre ambos hace énfasis Creonte en su indignación ante la pretensión de que un hombre de sus años tenga algo que aprender de quienes, como Hemón, son más jóvenes $\%$.

Dado que el término $v \varepsilon o ́ s$ frente a $\gamma \varepsilon \hat{\varepsilon} \rho \omega v$ y a $\pi \propto \lambda \propto$ เóç cubre todo el campo semántico de la primera parte de la juventud y de la edad madura, Hemón califica la conducta y las palabras de Creonte, que es

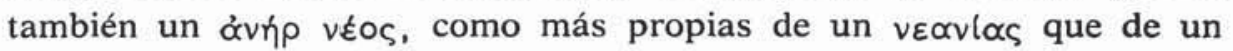

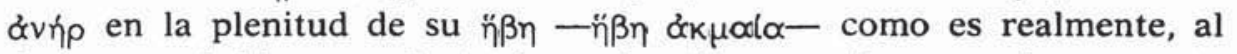
decir que "habla como lo haría un hombre excesivamente joven" - $৯ \varsigma$

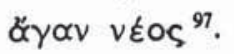

\section{Rasgos pertinentes de Creonte}

Creonte es la persona en la madurez de la vida que tiene en su haber, como antes decía al tratar de la estructura en que éste y el coro se oponen, un bagaje de convicciones estimadas inamovibles y acertadas, de comportamientos dictados por ellas y que se siente comprometido con la imagen que de él tiene su entorno social.

En la situación que nos ocupa, esas tres características se proyectan en la imagen del representante de una estructura familiar fuertemente patriarcal como es la griega, y de una estructura social basada en la práctica en el autoritarismo unipersonal como corría grave peligro de ser la griega.

Frente a él, el personaje juvenil de Hemón se caracteriza por poner de relieve las incongruencias y errores del esquema representado por Creonte.

93 S. Ant. 635, 638, 701.

94 S. Ant. 639.

95 S. Ant. 719.

9 S. Ant. 726-27.

97 S. Ant. 735. 
Creonte inicia y pone fin a su resis con dos términos que contienen en las nociones por ellos significadas la línea directriz de su forma de pensar y de actuar: la inicia el término $x \rho \eta^{98}$, que responde a la noción de "constituir obligación", la concluye el término $\pi \varepsilon 1 \theta \alpha \rho \chi l \alpha{ }^{99}$, que responde a la noción de "obediencia al principio de autoridad".

Constituye obligación para el hijo prestar obediencia incuestionable a los criterios y decisiones del padre. Es la obediencia ciega y sumisa de los hijos la que es motivo de orgullo $-\varepsilon b \chi_{0} \circ{ }^{\circ}{ }^{100}$ - para el padre, pues aporta a éste un principio de "utilidad»: en ese sentido se en-

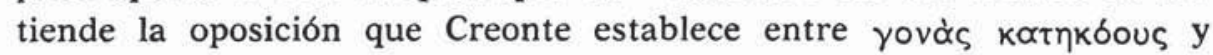
$\alpha v \omega \phi \varepsilon \dot{\lambda} \eta \eta \tau \alpha \tau \varepsilon \kappa v \alpha^{101}$. Califica a los hijos que no prestan sumisa obediencia al padre de $\alpha^{\alpha} \nu \omega \phi \varepsilon \lambda \eta \tau \alpha$, en la medida en que son para éste fuente de "conflictos internos" y de "pérdida de la estima social».

Del mismo modo, constituye obligación para todos los miembros de la familia prestar obediencia incuestionable al varón que ostenta el principio de autoridad en ella - cosa que no ha hecho Antígona- y para los ciudadanos al gobernante por ellos elegido $-\alpha^{\prime} \lambda \lambda \lambda^{\prime} \delta \nu \pi \dot{\delta} \lambda ı$

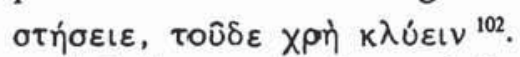

Asimismo, constituye obligación del padre, el varón y el gobernante velar por el prestigio de su autoridad, o sea, velar por el prestigio de su imagen. De ahí que Creonte defienda la idea de que solamente manteniendo la disciplina - кóonos- entre los miembros de la unidad familiar puede tener un respaldo de equidad para mantenerla en el estado ${ }^{103}$.

De ahí que mantenga la actitud de «no desmentirse ante los ciudadanos»104, dejando de llevar a efecto su propio decreto por ser un miembro de su familia quien lo ha desobedecido.

Después de la resis de Hemón, en la que éste defiende puntos de vista distintos a los suyos, se pone de relieve otra característica de Creonte. Es ella su convicción de que el hombreen la edad madura de suvida, comoes él, notiene nada que apren$\mathrm{der}$ de quienes son más jóvenes ${ }^{105}$. Ese mismo rasgo se pone de manifiesto en la actitud global de Creonte a lo largo de toda la con-

98 Cf. Th. D. Goodell, " $\chi \rho \eta$ and $\delta \varepsilon i », C Q ~ 8,1914$, pp. 9-102.

99 S. Ant. 676.

100 S. Ant. 641.

101 S. Ant. $341-42$ y 645.

102 S. Ant. 666-67.

103 S. Ant. 659 ss.

104 S. Ant. 657.

105 S. Ant. 726-27. 
versación con su hijo: habla él, pero no presta atención a lo que se le dice cuando no coincide con su criterio, como le censura Hemón.

Un tercer y último rasgo consiste en su actitud y palabras dictadas por el apasionamiento- - $p y n ́$ - ante la sorpresa que le produce el hecho de que su hijo haga juicios de valor individuales que no coinciden con los suyos. De ahí la desvirtuación de la realidad al atribuir las diferencias que Hemón tiene con él a la influencia del amor por Antígona.

Rasgos pertinentes de Hemón

El primer rasgo que destaca en Hemón, nada más hacer su aparición en escena, es su actitud respetuos a hacia su padre, unida al firme criterio de que su obediencia no es incues. tionable ${ }^{106}$ : Hemón sostiene que "prestará obediencia a Creonte siempre que éste lo guíe por el camino recto con criterios acertados»;

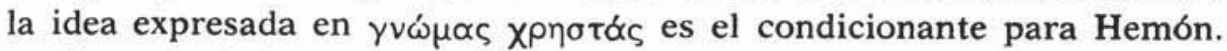

Después de la resis de Creonte, se detecta en el comienzo de la de Hemón la misma actitud de respeto, marcada por el uso de la moda-

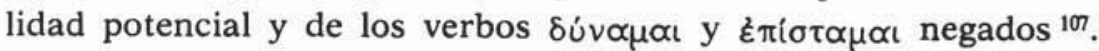

Hay otra característica muy importante que emana de su juventud. Frente a la edad de su padre y la situación vital que ésta lleva consigo, Hemón aún no está clausurado en la vida ni por la vida y portanto no ofrece una imagen impermeable de su persona, que aún no tiene, y lo que recibe de su entorno son verdades, no apariencias; al contrario que Creonte, que mantiene una apariencia ante su entorno y una apariencia recibe de él. Esta diferencia esencial es la que resalta Hemón al decir que a su padre no llega lo que piensa el hombre de la calle, mientras él lo sabe ${ }^{108}$.

El criterio directriz de toda la argumentación de Hemón se sigue

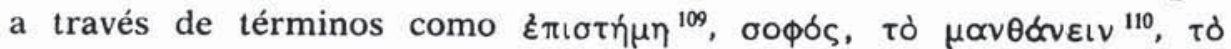
$\phi \rho \circ v \varepsilon i v^{111}, \alpha \mu \alpha \rho \tau \chi^{112}$. Por medio de ellos se van haciendo patentes los puntos débiles de los esquemas que defiende Creonte. El carácter inamovible de las convicciones y actitudes de Creonte tendría razón de ser si el ser humano tuviera por naturaleza "conocimiento recto"

\footnotetext{
106 S. Ant. 635-38.

107 S. Ant. 686.

108 S. Ant. $690-99$.

109 S. Ant. $720-21$

110 S. Ant. 710.

111 S. Ant. 755.

112 S. Ant. 743.
} 
$-\varepsilon \pi$ เ $\tau \pi \mu \eta$. Pero no es así, sino que lo que los dioses han hecho crecer en el hombre es la capacidad de tò фpoveîv -la inteligencia-; una capacidad potencial desarrollable, pero no una conquista definitiva.

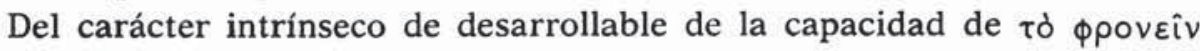

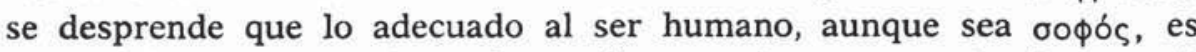
estar abierto a "aprender más y más", a ceder en sus criterios y actitudes y a cambiar prestando atención a los criterios ajenos, si merecen ser tenidos en consideración, aunque procedan de una persona más joven.

Este es el punto en que Hemón utiliza, ahora él, el término $x \rho \eta^{113}$ al sostener que constituye obligación prestar más atención a la conducta de la persona que al número de años que cuenta en su haber. Cualquier actitud que sea diferente a ésta, como es la de Creonte, al no ser la adecuada al ser humano, lo lleva a la $\alpha \mu \alpha \rho \tau l \alpha$.

\section{2) Deyanira/Yola}

En las Traquinias la oposición de edad yuvń/ veavlç: Deyanira / Yola desempeña una función muy destacada. Pero se da una peculiaridad importante, y es que no hay en la obra ninguna estructura formal literaria en que ambos personajes dialoguen entre sí, ya que la joven Yola es un personaje silencioso, pero presente.

No se encuentran por tanto términos de interpelación de una mujer hacia la otra.

La oposición $\gamma u v \eta ́$ / veđvls se desarrolla literariamente de una forma indirecta: en el prólogo ${ }^{114}$, en el que Deyanira habla de sí misma; en la primera parte del primer episodio, en la resis con que Deyanira se dirige al coro integrado por muchachas de Traquis ${ }^{115}$, que tienen la misma edad que la joven amante de Heracles - parlamento que tiene lugar antes de que ésta aparezca en la vida consciente de Deyanira-; y en la segunda parte del mismo episodio, en tres estructuras dialógicas sucesivas: Deyanira-Licas; Deyanira-Mensajero y Deyanira-Mensajero, Licas ${ }^{116}$.

Los términos pertenecientes al campo semántico de la edad se encuentran en el plano directo en la forma en que Licas se dirige a Deyanira utilizando el término $\gamma u v \eta^{117}$.

\footnotetext{
113 S. Ant. 729

114 S. $\operatorname{Tr} .148$.

115 S. $T r .141-77$.

116 S. $T r .229-496$.

117 S. $T r .393$, etc.
} 
En el plano relacional hay términos pertenecientes al campo semántico de la edad referidos tanto a una como a otra mujer: así Deyanira

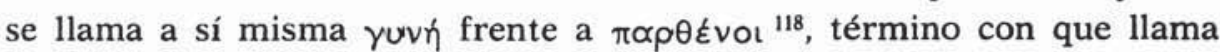
a las mujeres que integran el coro; $v \varepsilon \alpha v\left(\varsigma\right.$ llama a Yola y $v \varepsilon \omega \tau \varepsilon \rho \alpha^{119}$, utilizando el comparativo para marcar la diferencia de edad que hay entre ambas; de la misma manera que define su propia $\eta \beta \eta$ como "habiendo iniciado la trayectoria del declive" $-\phi \theta i$ vou ${ }^{120}$ - frente a la $\dddot{\eta} \beta \eta$ de Yola, que lo que inicia es el camino hacia su culminación

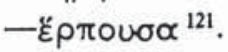

La circunstancia coyuntural que motiva el desvelamiento de las características diferenciales de las dos mujeres, es el amor de un hombre por la una, que conlleva el desamor por la otra, o puede conllevarlo. No obstante es sólo una circunstancia coyuntural; los rasgos que oponen a las dos edades de la vida son previos a cualquier circunstancia, y algunos de los que son propios de Deyanira se ponen de manifiesto mucho antes de que ésta conozca la existencia de Yola.

Es el personaje de la mujer en la madurez de su vida el que está caracterizado con unas marcas muy claras. El de Yola se esboza más bien por polarización frente a una serie de rasgos bien dibujados de Deyanira; aunque es la existencia de la mujer joven y su silenciosa presencia la que a su vez polariza a Deyanira, haciendo posible que se manifiesten otra serie de rasgos que le son propios.

Rasgos pertinentes de Deyanira

a) Rasgos que se manifiestan antes de conocer la identidad de Yola: tiene un pasado en el haber de su vida que pesa sobre ella con carácter condicionante. Lo juzga «infor-

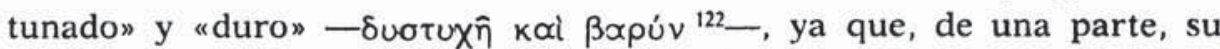
amor por su esposo ha sido para ella fuente de "miedo constante" - $\phi \delta$ ßo ${ }^{123}$ - y de "incertidumbre y ansiedad"; y de otra parte, ha conocido la soledad física y moral de su condición de mujer y madre. No desea a nadie - las jóvenes del coro a quienes se dirige- un pasado como el suyo, en un sentimiento de añoranza de su primera juventud, que le impulsa a decir ${ }^{124}$ : "ojalá no lo conozcas nunca por experiencia;

\footnotetext{
118 S. $T r .148$.

119 S. $T r .307$ y 551.

120 S. Tr. 548.

121 S. $T r .547$.

122 S. Tr. 5.

123 S. $T r .27-28$.

124 S. Tr. 143-50.
} 
ahora eres inexperta, ya que la juventud pace en sus propios campos... y entre placeres lleva una vida sin fatigas... hasta que una recibe el nombre de esposa en vez de soltera y toma parte en las preocupaciones de la noche, temiendo ya por el esposo, ya por los hijos".

El temor que le inspira el futuro es otra característica de Deyanira, un temor que se basa en las experiencias adquiridas en el pasado en un comienzo; y que, más adelante, ante la feliz noticia del triunfo de Heracles y su inminente regreso y el contraste con la compasión que le inspiran las prisioneras de guerra, se agudiza. Es un temor irracional en parte el de Deyanira, sin causa que pueda explicarlo, intuitivo; así los términos $\tau \alpha \rho \beta \varepsilon \hat{v}{ }^{125}, \delta \varepsilon \delta \delta \kappa^{126}$ que emplea; pero en parte es un miedo racional, provocado por la visión de la situación de las mujeres cautivas, cuyos hijos pide a Zeus que no vivan nunca ${ }^{126}$.

Es justamente la "compasión" -olktoৎ- que siente por el infortunio ajeno otra marca de su persona: «dignas de compasión» -olk.

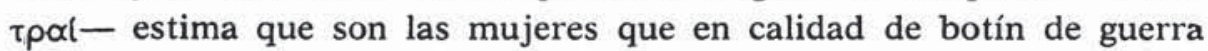
ha enviado Heracles ${ }^{128}$; un sentimiento de "compasión" la invade al ver sometidas a la esclavitud a quienes han nacido libres ${ }^{129}$. Y "compasión» le inspira más que todas Yola ${ }^{130}$ por el curso normal de una vida joven truncado y porque "es diferente» a las demás: así dice que es la única que en su actitud muestra unas cualidades de índole espiritual - $-\rho \circ \operatorname{cit}^{1}{ }^{131}$ - que ella piensa que denotan una doble cuna y una esmerada educación. La compasión que Deyanira experimenta por Yola no sólo viene dada por un sentimiento de solidaridad con el infortunio ajeno, sino también por un sentimiento de simpatía e interés por el que se intuye un igual.

b) Los otros rasgos de Deyanira se ponen de manifiesto una vez que ha conocido la identidad de Yola y su condición de amada por Heracles.

Al saber la verdad, se produce en el personaje una mutación interna y un desdoblamiento en la actitud hacia el exterior. Solamente ante el coro descubre la verdad de su pensar y sentir. En cambio ante los extraños -el mensajero y Licas - mantiene una imagen de apariencia.

\footnotetext{
125 S. $T r .297$.

126 S. Tr. 306.

127 S. Tr. 293-306.

128 S. $T r .243$.

129 S. $T r .228-302$.

130 S. Tr. $312-13$.

131 S. $T r .313$.
} 
Este es el desdoblamiento al que me refiero, muy bien reflejado literariamente en el carácter retórico que tiene el parlamento con que se dirige al mensajero y a Licas ${ }^{132}$, frente al carácter no retórico con que habla al coro ${ }^{133}$.

A lo largo de la resis dirigida al coro se va poniendo de relieve la mutación interna del personaje, que ahora queda a su vez caracterizado con unas marcas muy claras también. Son las siguientes:

La preocupación por la edad, su juventud en el cenit, que inevitablemente va a iniciar una trayectoria de envejecimiento, es fuente de angustia para Deyanira, al oponerse a ella la extrema juventud de Yola, que va a ir madurando progresivamente hasta alcanzar la ók $\mu$ ŕ. Es esta insalvable diferencia entre ambas mujeres lo que hace a Deyanira temer que mientras a ella se le va a dar el nombre de "la mujer" de Heracles, "su esposa" será la más joven ${ }^{134}$.

El temor que le inspira la diferencia de edad es el que motiva que su primer sentimiento de "compasión" hacia Yola se mute en un sentimiento de "miedo" - $\phi \delta \beta$

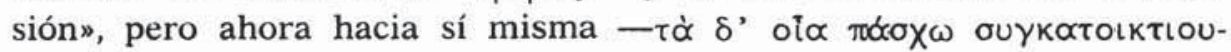
$\mu \varepsilon^{\varepsilon} \nu \eta{ }^{135}$.

Esos dos sentimientos, más que ser rasgos nuevos en el personaje, surgen por mutación de los ya existentes: si un miedo inconcreto había acompañado su pasado, en el presente éste se concretiza en un objeto; y la compasión que proyectaba sobre el infortunio ajeno igual que sobre el propio, ahora se proyecta sólo sobre el propio.

Son esos sentimientos los que inducen a Deyanira a adoptar un criterio de utilidad solamente para sí misma, cuya puesta en práctica es justamente el que la lleva a la $\alpha \mu \alpha p \tau i \alpha$.

\section{Rasgos pertinentes de Yola}

En las Traquinias, al contrario de lo que ocurre en otras obras de Sófocles, éste caracteriza a su personaje joven con sólo dos marcas: la del existir y la de la presencia silenciosa. El personaje de Yola, con su existencia y su presencia silenciosa real, o sentida, está presente en prácticamente toda la obra.

El rasgo más destacado de Yola es el hecho de que, por existir y estar presente, produce un desmoronamiento de los esquemas vitales

132 S. $\operatorname{Tr}, 436-69$.

133 S. $T r .531-87$.

134 S. $T r .550-51$.

135 S. $T r .535$. 
y de comportamiento de su antagonista, que aparecían configurados como una conquista definitiva.

Los demás rasgos de la joven se configuran por oposición a los que son propios de Deyanira: así, ella no tiene en el haber de su vida un pasado condicionante, pues su único pasado es la niñez; no añora la juventud porque la posee, ni teme su pérdida porque su futuro es alcanzar la cima de la juventud; no puede sentir compasión porque su situación es desventajosa y por tanto acreedora de compasión; y, si "siente miedo" - como puede conjeturarse de las palabras de Licas ${ }^{136}$ al referir que tan sólo se la ve llorar abrumada por el infortunio y de su misma actitud de silencio-, lo que en verdad hace es "despertar miedo».

\section{3) Odiseo/Neptólemo}

El prólogo de Filoctetes se abre con una estructura formal en la

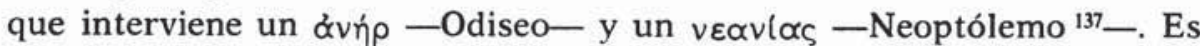
una composición literaria dialógica en la que alterna con la esticomitía el diálogo amplio.

Ambos hombres se encuentran ante una situación muy concreta: han sido enviados por el ejército griego a la isla de Lemnos con la misión política de conducir de nuevo a Filoctetes a Troya. Es Odiseo el que conoce el objetivo de la misión. Neoptólemo ignora tanto las relaciones pasadas con el ejército griego como el objetivo de la misión; él lo único que tiene que hacer es obedecer las órdenes de Odiseo y recibir de éste la información que él estime oportuna.

En la parte primera del éxodo hay una estructura dialógica esticomítica entre Odiseo y Neoptólemo ${ }^{138}$. En ella se produce el enfrentamiento violento entre los dos hombres, debido al cambio de conducta de Neoptólemo con relación a la misión que le ha sido encomendada.

Lo que opone a los dos hombres desde el comienzo es el criterio de utilidad, marginal a cualquier consideración ética que rige la conducta del ơvńp. Utilidad puesta al servicio del interés del estado, que lleva consigo en la práctica la ciega obediencia a la autoridad; frente a la ética del $v \varepsilon \propto v i \propto \propto \varsigma$ que, si bien en un principio se muestra como inculcada desde la infancia y por tanto perteneciente a normas de conducta familiares, al final acaba siendo una ética individual.

\footnotetext{
136 S. $T r .325-26$.

137 S. $P h .1-134$

138 S. Ph. 1222-1262.
} 
En el plano directo, ninguno de los dos utiliza ningún término de interpelación perteneciente al campo semántico de la edad. Odiseo es

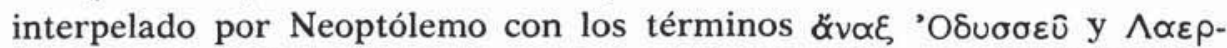
$\tau$ tou $\pi \propto \hat{\imath}{ }^{139}$. Y Neoptólemo es interpelado por Odiseo con el término 'A $\iota\left\llcorner\lambda \lambda \varepsilon \omega \varsigma \pi \propto \hat{\imath}{ }^{140}\right.$.

En el plano relacional, Odiseo emplea el término $v \varepsilon \varepsilon_{\circ}$ para referirse a él mismo cuando tenía la edad de Neoptólemo, frente a la que tiene en la actualidad ${ }^{141}$.

\section{Rasgos pertinentes de Odiseo}

En el prólogo, Odiseo pone en antecedentes al joven Neoptólemo de las relaciones existentes en el pasado entre Filoctetes y el ejército griego, así como de las relaciones entre Filoctetes y él mismo.

Unos pocos rasgos que le son propios se desvelan progresivamente. Es el hombre con un pasadoen el haber de suvida en el que ha habido elecciones de formas de actuar, que lo han vinculado a la política del ejército griego del que es uno de sus dirigentes, hecho que a su vez le ha venido marcando la necesidad de hacer nuevas elecciones y de adoptar formas de conducta en consonancia con sus vínculos. Su pasado le ha conferido una imagen ante los demás, al tiempo que ha comprometido su presente. $\mathrm{Y}$, además, su vida ha de seguir discurriendo en el campo de la acción como la de todo hombre en la

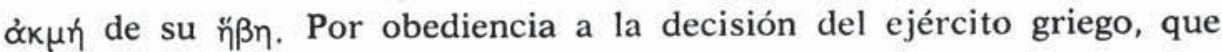
fue también su propia decisión, en el pasado abandonó al enfermo Filoctetes en la isla de Lemnos ${ }^{142}$.

Se caracteriza por una serie de criterios de carácter inamovible. Su criterio es que Neoptólemo en el presente, como él antaño, debe obediencia incuestionable a la autoridad ${ }^{143}$; así es recurrente la utilización que hace del término $\delta \varepsilon i^{144}$ para referirse al "carácter obligatorio" para Neoptólemo de llevar a cabo su misión, así

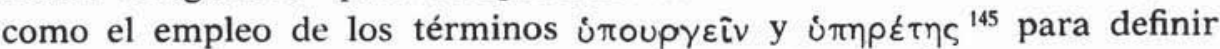
la situación del joven y la conducta que de él se exige.

Su criterio, a la hora de actuar, es el de anteponer la "conveniencia" o "utilidad" al servicio de los intereses del estado y del individuo, no

\footnotetext{
139 S. $P h .26$ y 87.

140 S. Ph. $50,57$.

141 S. $P h .96$

142 S. $P h .6$.

143 S. $P h .15$.

144 S. Ph. 50, 54.

145 S. $P h .53$.
} 
ignorando que ello contradice todo criterio ético, pero manteniendo que la ética ha de ser marginada en determinadas circunstancias. Así,

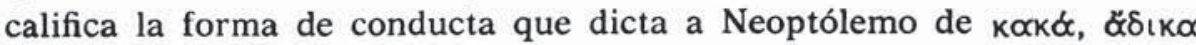
y óv $v \propto\left\llcorner\delta \tilde{\eta}^{146}\right.$. Y en un parámetro distinto está el criterio de utilidad $-\pi \rho \varepsilon \pi \varepsilon \mathrm{t}^{147}$-, término que emplea con carácter recurrente. De la acción guiada por tal criterio se deriva el "provecho" -

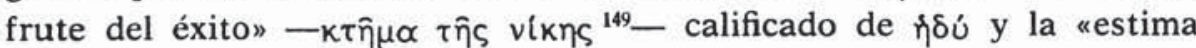

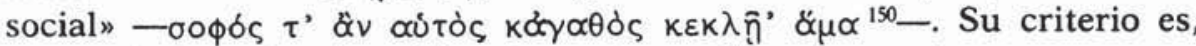
en lo relativo a la ejecución misma de un plan que conduzca con garantías al éxito, que el mejor medio es seducir al interlocutor por medio de la palabra, no de la acción. Es la edad lo que ha enseñado a Odiseo "la fuerza seductora de la palabra» ${ }^{151}$.

Desde este punto de mira, no se puede hablar de $\alpha \mu \alpha \rho \tau i \alpha^{152}$ en la forma de proceder, si ella ha dado como fruto la obtención de "lo que conviene». Mientras que la desobediencia a la autoridad se juzga de "forma de actuar carente de inteligencia práctica" 153 y debe inspirar un sentimiento de "temor" - $\phi \delta$ ßos ${ }^{154}$.

\section{Rasgos pertinentes de Neoptólemo}

En la primera estructura formal en que son oponentes Odiseo y Neoptólemo se pone ya de manifiesto un rasgo propio del veavias que lo diferencia del óvńp. Es este rasgo la posesión de un código ético no individual, sino familiar ${ }^{155}$. El único pasado con que el joven Neoptólemo cuenta es la niñez y la adolescencia. A lo largo de este primer período de la existencia ha sido un ser meramente receptivo. De una parte, se le han inculcado por enseñanza unas normas de conducta que constituyen la ética de la sociedad familiar a la que pertenece; así Odiseo, pensando en esa enseñanza, le dice que "aunque oiga de él cosas nuevas que antes no haya oído, no olvide que su obligación es obedecer» ${ }^{156}$. De otra parte, se trata

\footnotetext{
146 S. Ph. 79-85.

147 S. Ph. 111.

148 S. Ph. 111.

149 S. Ph. 81.

150 S. Ph. 119.

151 S. Ph. 96-99.

152 S. Ph. 1227 ss

153 S. Ph. 1245.

$154 \mathrm{~S}, \mathrm{Ph}, 1250$

155 S. Ph. 52-53.

156 S. Ph. 50-53.
} 
de una moral basada en la propia naturaleza, de ahí el empleo de los

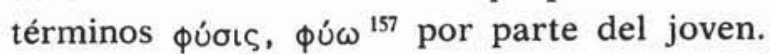

El código ético, que constituye una $\pi x i \delta \varepsilon l \alpha$ y responde a una фúoıs, suma dos principios básicos: el respeto y obediencia a la persona mayor, a la autoridad; y el principio que prohíbe la utilización de una conducta en la que "la intención del individuo" no transcurra por el mismo sendero que "la imagen que los demás reciben de él» para alcanzar ningún objetivo. Son precisamente estos dos principios básicos los que entran en conflicto dentro de su persona, ya que proceder de acuerdo con el primero significa transgredir el segundo.

No obstante, Neoptólemo en un principio tan sólo manifiesta un

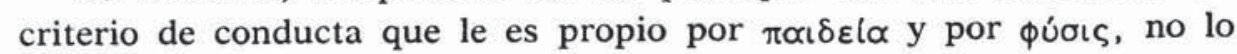
defiende hasta sus útlimas consecuencias, e incluso pone en duda su validez absoluta, al hallar frente a él tanto su obligación de prestar obediencia a la autoridad como las convicciones del hombre adulto al que acompaña una suma de temporales experiencias. En el marco de esta duda hay que entender el miedo a que se le considere un traidor si desobedece la insinuación a Odiseo de que modifique su orden en lo referente al procedimiento $\mathrm{y}$, por fin, el hecho de que acceda a actuar según las directrices del đơvíp atraído por la consideración social que de ello va a derivarse para él.

Al final de la obra, en la segunda estructura formal en que ambos hombres aparecen como oponentes, el rasgo pertinente de Neoptólemo es la posesiónde un códigoéticopropio, individual, no familiar, producto de la primera experiencia que le ha tocado vivir y que lo lleva a realizar su primera libre elección.

$\mathrm{Si}$ al comienzo de la obra el joven solamente exponía el códico ético

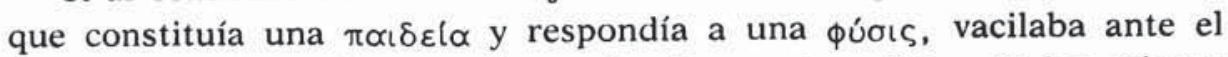
deber que le imponía su reciente vínculo con la política de los griegos y lo marginaba ante la idea del éxito, en cambio ahora defiende y pone en práctica con absoluta firmeza su propio código ético recién conquistado, que lo lleva a romper sus vínculos de obediencia a las directrices políticas de sus superiores y, en consecuencia, al enfrentamiento abierto y violento con su oponente ${ }^{158}$.

\section{4) Agamenón/Ifigenia, Aquiles}

En el segundo episodio de Ifigenia en Aulide se inserta una estructura dialógica en esticomitía en la que intervienen un ơvin -Agame-

157 S. Ph. 88.

158 S. $P h .1222-1258$. 


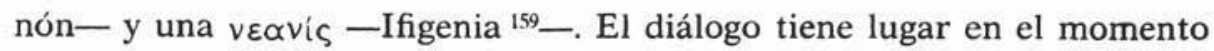
en que Ifigenia, acompañada de su madre, ha llegado a Aulide llamada por su padre con el supuesto proyecto de que contraiga matrimonio con Aquiles.

La primera escena del cuarto episodio la constituye otra estructura formal en la que intervienen padre e hija, compuesta esta vez por dos resis de Ifigenia y Agamenón respectivamente, cuando ya ella conoce el verdadero motivo de su viaje a Aulide ${ }^{160}$.

En el tercer episodio hay una estructura formal en la que interviene

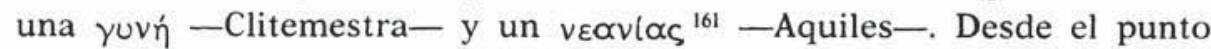
de vista de la composición literaria la estructura empieza siendo dialógica, es interrumpida por la entrada en escena de un anciano servidor de Clitemestra que pone a ésta y al joven Aquiles en antecedentes del verdadero motivo del viaje de Ifigenia a Aulide; y continúa con dos resis sucesivas de Clitemestra y Aquiles respectivamente, para terminar en composición dialógica alternando con la esticomitía.

La segunda escena del cuarto episodio presenta una estructura for-

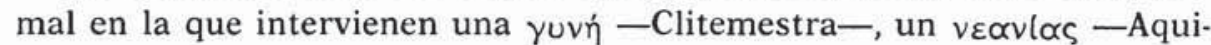
les- y una $v \varepsilon \propto v i \varsigma$ - Ifigenia-. La composición literaria consta de una estructura en antilabé entre Clitemestra y Aquiles, seguida de una resis de Ifigenia que se continúa con un diálogo entre ésta y Aquiles, para concluir con una esticomitía entre madre y hija ${ }^{162}$.

En las estructuras en que aparece Clitemestra no se observa oposición con los personajes jóvenes basada en la noción de edad. En las estructuras en que intervienen Aquiles y Clitemestra lo que se pone de relieve son los rasgos propios del veavlas en su diferencia con los del ớvíp, ya que Aquiles y Agamenón no aparecen juntos en escena en ningún momento.

En la estructura en que intervienen Clitemestra e Ifigenia lo que se pone de manifiesto son rasgos propios de la joven, que completan aquellos que se desvelan en las estructuras en que intervienen padre e hija.

En lo referente al léxico se encuentran los siguientes términos: en el plano interpelativo Ifigenia se dirige a su padre con el término

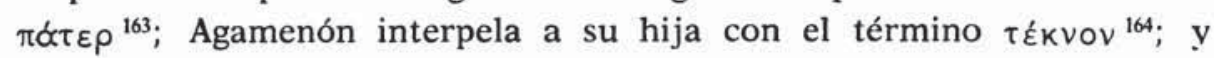

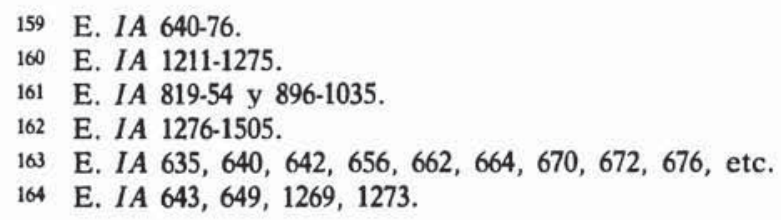


Aquiles es interpelado por Clitemestra con los términos $\tau \dot{\varepsilon} \kappa \nu \circ v$ NnpñS०ऽ y $\pi \propto \hat{L} \Pi \eta \eta \lambda \varepsilon \omega \varsigma^{165}$, que ni pertenecen al campo semántico de la edad, ni guardan relación colateral con él. En el plano relacional a Ifigenia se la llama $\kappa o ́ p \eta^{166}$ y $\pi \propto \rho \theta \varepsilon \dot{\varepsilon} \vee \varsigma^{167}$, y a Aquiles $v \varepsilon \alpha v i \alpha \varsigma^{168}$, términos que cubren sólo el campo semántico de la primera parte de la juventud.

Rasgos pertinentes de Agamenón

Dos son los rasgos que caracterizan al hombre en la $\alpha k \mu \eta \dot{~ d e ~ s u ~}$ $\eta \eta \beta \eta$. Son ellos los que pertenecen a las esferas "del querer hacer" y "del tener que hacer y poder hacer" respectivamente. Las circunstancias ponen de relieve que Agamenón no puede conciliar ambas esferas, de ahí el ser humano roto internamente y débil externamente. El léxico va marcando de una forma recurrente la oposición entre esas dos esferas, bien significadas por los términos $\theta \dot{\varepsilon} \lambda \varepsilon \iota \nu$ y $\delta \varepsilon \hat{\imath}$ respectivamente.

Todas las características del personaje están sintetizadas en la respuesta que da a su hija, cuando ésta le pide mimosamente que no vaya a la guerra y se quede en casa con sus hijos. Es ésta la contestación de Agamenón: "eso es lo que yo quiero y sufro de no poder hacer lo que quiero" ${ }^{169}$.

La esfera del $\theta \varepsilon \lambda \varepsilon \varepsilon เ \nu$ se concretiza en el amor que el ơvip siente por su hija. Pero su significación es mucho más amplia: el amor por Ifigenia es solamente la concretización en la obra de un mundo interno complejo y solitario. La esfera del $\theta \varepsilon \hat{\varepsilon} \lambda \varepsilon$ เV significa todo el campo de los sentimientos de Agamenón: ellos le dictan la ruptura con las estructuras con las que está comprometido, con los vínculos que sus elecciones anteriores le han llevado a contraer con la comunidad griega y con su situación de cabeza responsable del futuro de dicha comunidad.

En el primer diálogo con Ifigenia, el drama interno que vive Agamenón adquiere su máxima magnitud por dos razones: una de ellas es la de no poder expresarlo al exterior con la palabra; la otra, la de tener ante él a la joven, que tan sólo sabe de la esfera de los sentimientos, de la esfera del $\theta \varepsilon \hat{\varepsilon} \lambda \varepsilon \iota \nu$.

En cambio, cuando se formula explícitamente es en la segunda estructura formal en que intervienen padre e hija, cuando aquél ya no se ve obligado al silencio, ni a la palabra ambigua. Ahora formula sus

\footnotetext{
165 E. IA 896.

166 E. $I A 671,679$.

167 E. IA 908.

168 E. IA 933.

169 E. $I A 657$
} 
sentimientos en una sola frase, al afirmar "que es consciente de lo que es objeto de compasión y de lo que no lo es, que ama a sus hijos, pues en caso contrario sería un demente» ${ }^{170}$. Y en el mismo lugar, a continuación, cuando expresa su condición de hombre comprometido por unos vínculos que estima y siente como irrompibles, que han fundido la "esfera del deber" con la del "tener necesariamente". De ahí que libre a su hermano Menelao de culpa ${ }^{17}$. Es la estructura misma -la comunidad griega y su propia condición de hombre público- la que marca el camino del deber - $\delta \varepsilon \hat{\imath}$ - que se convierte en esclavitud

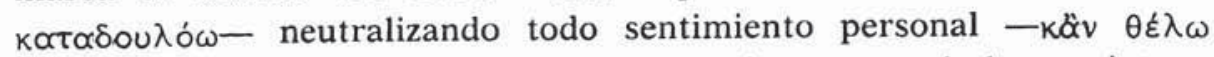
$\kappa o ̛ ̉ v ~ \mu \eta \dot{~} \theta \dot{\varepsilon} \lambda \omega-\mathrm{y}$ reduciéndolo a víctima instrumental de sus intereses ${ }^{172}$.

\section{Rasgos pertinentes de Ifigenia}

En la primera estructura formal en que son oponentes Agamenón e Ifigenia se ponen de relieve los siguientes rasgos de la joven:

Espontaneidad de actitud y palabra, que se manifiesta en la expresiva alegría ante la presencia de su padre tras la añoranza que ha experimentado por la larga ausencia; en las mues tras de alborozo de que hace gala al volver a verlo ${ }^{173}$; en la actitud mimosa que quiere acaparar la atención del padre para ella sola ${ }^{174}$; en sus intentos de alegrarlo arrancándole una sonrisa, para lo que propone "hablar bobadas" 175 , y en el anhelo de presencia que la lleva a querer, o bien retenerlo a su lado, o desear el imposible de convertirse en su compañera de viaje ${ }^{176}$.

Ingenuidad y perspicacia al tiempo constituyen otro rasgo de la joven, que se manifiesta en el hecho de que perciba en el rostrodel ser querido los más mínimos detalles de preocupación a pesar de su total ignorancia de que exista causa alguna que los motive; de ahí que se extrañe ante la contradicción de que su padre afirme estar alegre y, en cambio, su semblante no se muestre sereno. Ella no concibe que pueda recibir daño alguno del ser querido ${ }^{17}$, pero, pese a ello, advierte algo desconcertante tanto

$\begin{array}{ll}170 & \text { E. IA } 1255-56 . \\ 171 & \text { E. IA } 1269 \mathrm{ss} . \\ 172 & \text { E. IA } 1269-72 . \\ 173 & \text { E. IA } 640 . \\ 174 & \text { E. IA } 646 . \\ 175 & \text { E. IA } 654 . \\ 176 & \text { E. IA } 666 . \\ 17 & \text { E. IA } 644 .\end{array}$


en su conducta como en su rostro; así, cuando ve a su padre llorar contra su voluntad, alegando a modo de explicación que llora porque la ausencia de Ifigenia será prolongada, la juvenil ingenuidad del «no sé» 178 de la veavíc con relación a lo que Agamenón quiere significar, es calificada por el padre de "palabras perspicaces» que lo impulsan más al llanto.

Otro rasgo es 1 a a dmiración que siente 1 a joven por el hombre mayor, por sus empresas, que se le antojan un mundo maravilloso e inalcanzable: ella no sabe calcular la medida del espacio que va a separarla del padre y pregunta que dónde está ese lugar al que Agamenón va a conducir a sus tropas ${ }^{179}$.

En la segunda escena del cuarto episodio, en la estructura en que intervienen Clitemestra, Aquiles e Ifigenia, la joven aparece con un nuevo rasgo. Consiste éste en que ha comprendido que la "esfera del querer hacer" puede no coincidir con la "esferadel deberyel poder hacer». En otras palabras, la $v \varepsilon \propto v l \varsigma$ ha comprendido de una forma intuitiva el complejo universo en que se mueve el ¿́vinj; de ahí que acepte el sacrificio de su persona en beneficio del prójimo - la causa común de los griegos, las estructuras con que su padre está comprometido- y que pida a Clitemestra que no guarde rencor a su marido. Es, pues, por fin, el don grat u i to de su ser el último rasgo de la joven ${ }^{180}$.

\section{Rasgos pertinentes de Aquiles}

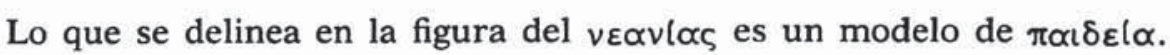
Lo importante, a mi modo de ver, radica en que se cifra una cierta esperanza en que el tipo de $\pi \propto\llcorner\delta \varepsilon l \alpha$ que ha recibido Aquiles no llegue a dar nunca hombres inmersos en situaciones reales como aquella en

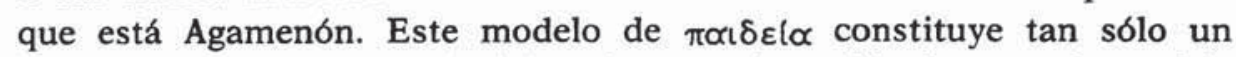
esbozo, en el que los principios de autoafirmación juegan al servicio de una ética de solidaridad y defensa del débil.

Hay en el joven un respeto a las normas sociales; urb a nidad es en realidad lo que aquí se significa con el término $\tau \dot{0}$ $\sigma \omega \phi \operatorname{cov\varepsilon îv}^{181}$ para definir el sentimiento de $\alpha \delta \delta \omega \varsigma^{182}$ que Aquiles expe-
178 E. IA 652.
179 E. $I A 662$.
180 E. IA $1276-1509$.
181 E. $I A 824$.
182 E. $I A 821$.

LI, $2.0-5$ 
rimenta al ver a una mujer de alta cuna en lugar tan insólito como es un campamento militar.

El joven se erige en "benefactor" $-\varepsilon \dot{\varepsilon} \varepsilon \rho \hat{\varepsilon}^{\prime} \eta \varsigma^{183}$ - de la causa del débil, como lo son personajes que encarnan al "rey justo»-Teseode tantas tragedias, y la aplicación de este término a un veavías es una verdadera novedad, independientemente de su éxito o fracaso en la empresa.

Su conducta está dictada por principios de autoafirmación: así, se trata de defender su ővo $\mu \propto$ ante el avasallamiento de que es víctima por parte de los dirigentes del ejército ${ }^{184}$. Pero también hay otro principio de autoafirmación, ya no vinculado "al prestigio heredado", sino a una

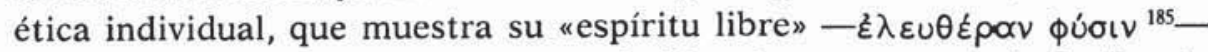
y se pone de manifiesto al expresar la idea de que "prestará obediencia

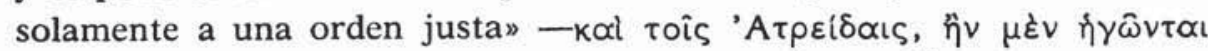

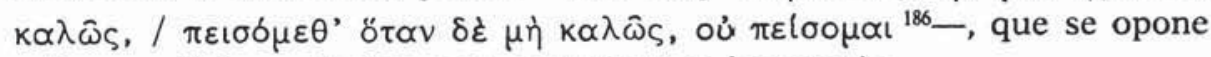
a los condicionamientos que esclavizan a Agamenón.

Ambos móviles juegan al servicio de otros valores éticos, esta vez cooperativos: así la "compasión" -olktos- que el dolor ajeno despierta en él ${ }^{187}$; la preferencia de "la persuasión» a la fuerza para llegar a un acuerdo con el entorno social ${ }^{188}$; y el preconizar una "conducta mesurada» $-\mu \varepsilon \tau \rho l \omega \varsigma$ - en la vida ${ }^{189}$.

5. Consideraciones sobre las edades de la vida fuera de estructuras formales con dos oponentes

Fuera de las estructuras de forma basadas en la presencia de oponentes de diferente edad, en la tragedia se encuentra la reflexión sobre los períodos de la vida humana en solos líricos o narrativos a cargo de un solo personaje y en corales.

Tanto los solos como los corales constituyen desde el punto de vista formal una línea de continuidad con la lírica arcaica. En éstos, de igual modo que en aquélla, se encuentra una reflexión acerca de las edades del hombre.

\footnotetext{
183 E. IA 1430.

184 E. $I A 944-47$, etc.

185 E. $I A 930$.

186 E. $I A$ 928-29.

187 E. $I A$ 932-34.

188 E. $I A 1011$ y 1013.

189 E. $I A$ 919-27.
} 
Ni los corales, ni los solos de la tragedia contienen una filosofía desgajada de la contenida en la obra a la que pertenecen. No obstante su vinculación con la obra en que se insertan, la doctrina que se encuentra en solos y corales innova poco con relación a la que veíamos de la lírica arcaica, a diferencia de lo que ocurre en las estructuras de forma integradas por oponentes de diferente edad, en las que se observan innovaciones importantes junto con una matización mucho mayor.

A continuación vamos a citar los rasgos que caracterizan a $\ddot{\eta} \beta \eta$ y a $\gamma$ ү̂pors, ya que la oposición aquí se establece sobre dos términos.

Rasgos luminosos caracterizan a $\dddot{\beta} \beta \eta$ : «la más hermosa de las posesiones humanas" - $\kappa \alpha \lambda \lambda$ ( $\sigma \tau{ }^{190}$ — la considera el coro de Heracles loco; también el mismo coro predica de ella su distintivo de «amable» $-\phi\left(\lambda \circ{ }^{191}\right.$ - y de "preferible al poder y a la riqueza" ${ }^{192}$. Para la anciana Hécuba la juventud de su hija Políxena es calificada como «apoyo, guía, alegría, consuelo y olvido de los pesares» ${ }^{193}$.

Pero también rasgos sombríos son inherentes a este período de la vida: «la imprudencia» que arrastra al error, dice el coro de ancianos de los Persas refiriéndose a Jerjes y al ejército que lleno de ciego entusiasmo ataca a un pueblo libre ${ }^{194}$; y el coro de Edipo en Colono predica de ella la «fugacidad» 195 .

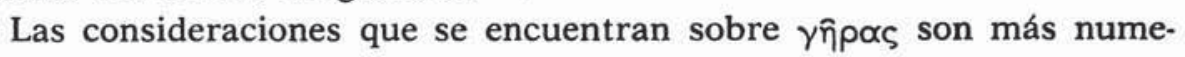
rosas y más importantes cualitativamente.

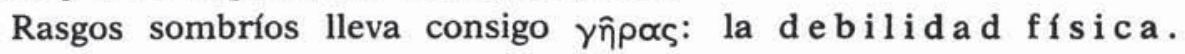
Así el anciano coro de Agamenón se opone a "los hombres de acción"

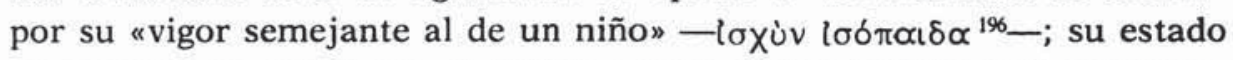
se compara en imágenes "al follaje reseco de los árboles y al espejismo de un sueño aparecido en pleno día» ${ }^{197}$. La "falta de fuerzas" - ¿kpo$\tau \hat{\varepsilon} \varsigma$ - lamenta el coro de Edipo en Colono ${ }^{198}$; el "vacilante caminar del $\gamma \hat{\varepsilon} \rho \omega \nu$, sin vigor para dejar en el suelo la huella de su paso» ${ }^{199}$, «la necesidad de un bastón como asidero ${ }^{200}$, «el cuerpo tembloroso» metafóricamente aludido al decir que el $\gamma \hat{\varepsilon} \rho \omega \nu$ es $\alpha$ sólo palabra y apa-

190 E. $H F 647$.

191 E. $H F 636$.

192 E. $H F$ 642-44.

193 E. Hec. 279-81.

194 A. Pers. $12-13,73,725,744,749,781-82$.

195 S. EC $1229-30$.

196 A. $A .9495$.

197 A. A. $79-82$.

198 S. EC 1236.

199 E. $H F 124$.

200 E. $H F 108$. 
riencia de sueños" ${ }^{201}$, que canta el anciano coro de Heracles loco. Hécuba en la obra de su nombre se refiere a su "paso lento, al bastón en que apoya su caminar», a la "necesidad de sostenerse en otras personas" expresada por la reiteración de los verbos con que se dirige

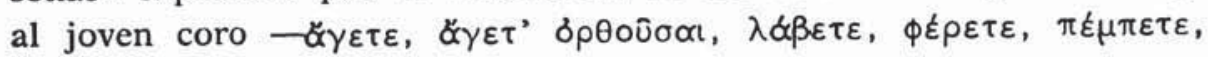

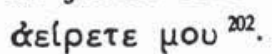

La a usencia de belleza: el "cuerpo marchito» que lamenta el coro de Agamenón - $\sigma \alpha \rho \kappa \curlywedge ~ \pi \alpha \lambda \alpha \mid \hat{\alpha}^{203}-\mathrm{y}$ las ancianas que integran

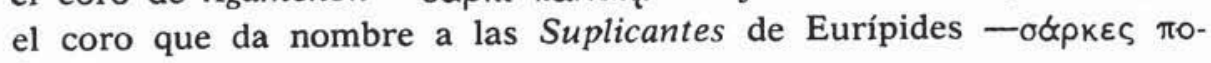
$\lambda\left(\alpha,{ }^{204}\right.$.

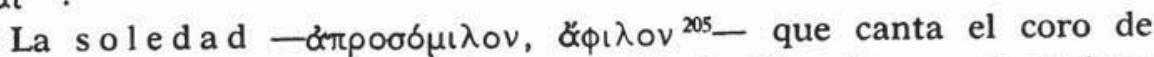
Edipo en Colono; y en el mismo sentido la idea de que el anciano "arrastra una existencia no inmersa en los instantes temporales del cotidiano vivir», anclada en un mundo, no compartido, de recuerdos tan sólo en un pasado sin aperturas al futuro.

La a usencia de metas a conquistar significada por la imagen de «una nube errante, arrastrada por vientos de inclemencia» 206 ; o bien por la de «un acantilado batido por olas invernales» ${ }^{20}$.

La herida irrestañable de la consciencia de los e rrores cometidos a lo largo de la vida, y el dolor de no disponer de otro ciclo temporal para rectificarlos ${ }^{208}$.

Rasgos luminosos comporta también la última etapa de la existencia humana: la debilidad física no impide que el coro de Agamenón sostenga la que ya era idea solónica de que el $\gamma \hat{\varepsilon} \rho \omega v$ siempre sigue teniendo

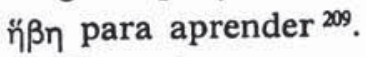

El anciano coro de Heracles loco resalta el contraste entre "su cuerpo tembloroso» y la fortaleza moral, «el ánimo que no abandona» 210.

En la misma obra, el anciano «no renuncia a su unción con las obras de la creatividad humana»; y su edad no le impide tener parte en los goces de la vida, en "la creación vivida y viviente: el canto, la danza y el vinos ${ }^{211}$.
201 E. $H F 1$.
202 E. Hec. 59 ss.
203 A. A. 72.
204 E. Supp. 50.
205 S. EC 1236-37.
206 E. Supp. 958-60.
207 S. EC 1240 ss.
208 E. Supp. 655-56.
209 A. $A .584$.
210 E. $H F 107$ ss.
211 E. HF 673-95. 
Es, por fin, característica de $\gamma \hat{n} \rho \alpha_{s}$ suscitar respeto, habiendo un solo lugar en que se dice que va acompañada de la a u sencia de estima social - $\alpha \tau \alpha \mu \mu \varepsilon \mu \pi \sigma^{212}$.

\section{CONCLUSIONES}

Se observa en la tragedia la pervivencia de los dos sistemas léxicos concernientes al campo semántico de la edad, que estudiábamos en la parte primera de este artículo.

Pero, mientras en solos y corales se desarrolla solamente el sistema que opone $\ddot{\eta} \beta \eta$ a $\gamma \eta \hat{p} \propto \varsigma$, , en cambio en las estructuras formales del teatro, en las que intervienen oponentes de diferente edad, encontramos desarrollado el segundo sistema: el que opone una primera juventud

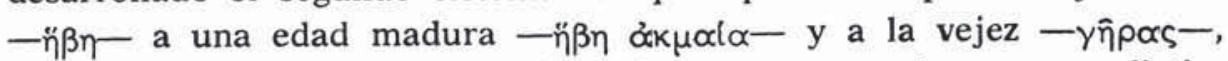
introduciendo novedades y cambios importantes en las marcas distintivas de cada uno de los períodos de la vida del hombre y en la valoración de las mismas.

\section{Rasgos pertinentes de la primera juventud}

Espontaneidad de actitud y palabras, así sobre todo en Ifigenia, pero no solamente en ella, también en personajes masculinos como Hemón, Neoptólemo, Aquiles.

Ingenuidad y perspicacia, magistralmente descrita en el personaje de Ifigenia, pero también de una forma menos tangible en Hemón, Aquiles y Neoptólemo, o sea, en varones.

Don gratuito del propio ser que veíamos en Antígona, Ismena e Ifigenia, como se da en otros personajes jóvenes de muchas obras de Eurípides, que, al no entrar en estructuras formales en que la noción de edad es pertinente, no han sido estudiados aquí: Meneceo de las Fenicias, Políxena de Hécuba o Macaria de los Heraclidas.

Fragilidad y dureza expuestas con magníficas y recias pinceladas en las jóvenes Antígona e Ismena, pero no sólo en ellas. Esta bipolaridad se encuentra asimismo en Aquiles, Neoptólemo, Ifigenia y Yola. De ahí, el nacimiento de otra bipolaridad que caracteriza a la primera etapa de la juventud: el sentimiento de temor y el hechode suscitar temor en el hombre maduro: Yola es el

\footnotetext{
212 S. EC 1235.
} 
más magnífico exponente, pero también de una forma menos tangible Neoptólemo, Hemón e Ifigenia.

Receptividad y determinación, receptividad que se manifiesta en el respeto que el $v \varepsilon \alpha v(\alpha \varsigma$ s siente por el đóvíp: así Hemón, Neoptólemo, Aquiles, Antígona e Ismena; en el silencio de Yola; en la admiración por su padre de Ifigenia. Pero siempre hay una determinación manifestada en el varón en "capacidad selectiva y crítica», en conquista de un código ético individual, en reflejo de un determinado modelo de $\pi \propto \delta \varepsilon l \propto$ : Hemón, Neoptólemo y Aquiles; y en la mujer en una "capacidad conciliadora" que lima asperezas, que ejerce la dinámica de crear amor y solidaridad: Antígona, Ismena, Ifigenia y, a la larga, la propia Yola.

\section{Rasgos pertinentes de la edad madura}

Las dos marcas que, sin ninguna excepción, son distintivas de la segunda parte de la juventud radican en: el compromiso del hombre con su propio pasado, con sus elecciones anteriores y con la imagen que de éltiene el entorno, que integran su identidad presente.

$Y$ en su inmersión en la esfera de la acción.

Estos rasgos acompañan a todos los personajes estudiados aquí.

Sometidos, por el compromiso con su pasado, a las esferas del xpŕ y el $\delta \varepsilon \tilde{\imath}$ - Creonte, Odiseo, Agamenón, Deyanira, Etéocles y Polinicese inmersos por su presente en la «esfera de la acción», afloran todos los móviles de la naturaleza humana, todos los sentimientos y todas las contradicciones. Así, la disyunción entre la esfera del $\chi \rho \hat{y}$ y la del $\theta \hat{\varepsilon} \lambda \varepsilon\llcorner v$ que observábamos en Agamenón, con su sometimiento a los enrejados del pasado, que aboca a esclavitud, miedo y cobardía; el u ti litarismo colectivo - $\omega \phi \varepsilon \lambda l \alpha-$ de Odiseo; el utilitarismo individual de Admeto y la propia Deyanira, o sea, el egoísmo entremezclado con el miedo - $\phi \delta \beta \circ \varsigma$ - muy tangible en Deyanira, menos tangible en Odiseo, pero no menos subyacente, y con la cobardía

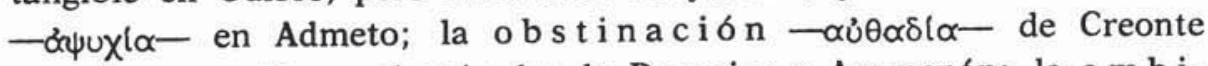
que aboca en ußpıs, el miedo de Deyanira y Agamenón; la a mbición - $\tau \iota \mu$ - de Etéocles y Polinices.

A veces actúan movidos por la pasión - $\dot{p} y \hat{n}-$, así Creonte, Etéocles, Polinices y Deyanira, pese a su voluntad; porque no hay que olvidar que ella es la única mujer y el poeta palía sus sentimientos adornándolos con "la mesura intencional" y "la mesura verbal», para que las estructuras sociales puedan aceptar a uno de los más bellos 
personajes femeninos que el tiempo ha querido conservar para nosotros. Otras veces, en cambio, actúa movido por el más puro cál cu 10 , así Odiseo.

A veces, el resultado de la acción, de la "suprema libre elección", de la libertad de que se puede hablar dentro de la dependencia de una esfera de "necesidad», lleva a la conmoción íntima de que hablan Creonte y Deyanira, a la resignación $-\varepsilon$ Ł̌eเv- de Creonte, o bien a la "resignación suprema" de Deyanira. Otras veces, lleva al sometimiento a la esfera de la necesidad-Agamenón-, y, otras todavía, a la pragmática defensa de esa esfera de necesidad, identificada con la de la liber$t$ a d, así Odiseo.

Quizá el camino más afortunado que las circunstancias abren ante el hombre maduro, a través del cual la progresión del tiempo humano aboca al presente de su última edad - $\gamma$ ñpos-, edad de luces y de sombras como todas las otras, pero sobre las otras de "conocimiento de las luces y las sombras", sea el camino de la $\varepsilon \mu \pi \varepsilon ı$ lol $\propto$, que comporta un factor de "resignación", pero que no es solamente resignación, pues el sendero de la $\varepsilon \mu \pi \varepsilon$ เ $\operatorname{lo}_{\alpha}$ es un sendero sin valla.

\section{Rasgos pertinentes de la vejez}

Debilidad física y fortaleza moral, bien patente en Yocasta y Edipo, pero no solamente en ellos, sino en corales como los de Heracles loco o Agamenón. Incluso toda la escena de Eurípides se llena de ancianos, caracterizados por esta bipolaridad: Hécuba, Yolao, Anfitrión, el coro de madres que integra las Suplicantes.

Añoranza por la ausencia del joven amado, que, habiendo sido la proyección de uno mismo, no se sabe cómo ha conquistado su "alteridad". Sentimiento de $\pi \delta \theta_{0}$ s que despierta el de sole dad, el de vaciedad que emana de uno mismo, y Yocasta lo percibe como fluyendo de las paredes vacías de una casa vacía.

Existencia al margen de la esfera de la acción, que opone a Edipo a sus hijos, a Yocasta a los suyos e incluso al mismo Feres a Admeto. Y que lleva a $s$ aberse $s$ in metas futuras, a la consciencia que tortura del tiempo pasado esfumado no se sabe cómo e irrecuperable, al vivir inmerso en un universo de recuerdos que se convierten en "recreación" de la existencia vivida, al margen de la acción sentida como «lo ajeno», pero de la que el anciano se siente solidario. 
Valoración de la existencia como el supremodon otorgado a l hombre. Así Feres como más claro exponente, pero no único; también Yolao, Anfitrión, Peleo. De ahí brota la unción del anciano con las obras del amor: las artes y la naturaleza, que canta el coro de Heracles loco.

Experiencia con el mundo y del mundo $-\varepsilon \mu \pi \varepsilon$ iplo - de que habla Yocasta, que la lleva a estar en posesión de lo que designa con

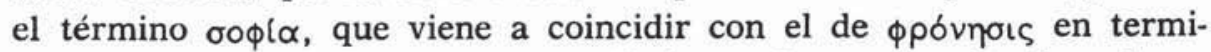
nología del coro de Antigona; oponiéndose a la $\alpha \mu \alpha \theta i \alpha$ manifestada en

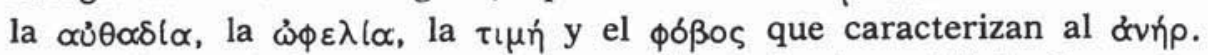
Y que lleva asimismo a estar en posesión de la ductilidad - $\tau \tau \varepsilon ́ p-$ $\gamma \varepsilon เ v$ - que dice Edipo y de la serenidad - rouxla - que preconiza Yocasta y marca la conducta del coro de Antigona, que se opone tanto a la bpyń de Creonte, Etéocles o Polinices, como al "cálculo» de Odiseo.

La experiencia y sus conquistas hacen factible la cap a cidad de

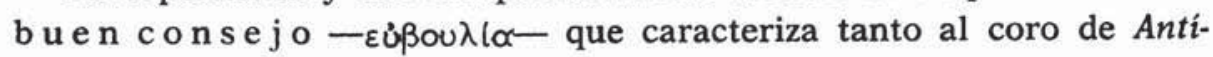
gona como a la anciana Yocasta.

Por primera vez en la historia de Grecia se exalta como edad luminosa la primera parte de la juventud. Por primera vez Sófocles y Eurípides llenan su escena de jóvenes. Una sociedad en crisis pone su mirada esperanzada en quienes pueden aportar savia renovadora frente a los egoísmos, al "abuso del poder otorgado», a las clausuras esclavizantes que han introducido la desarmonía en la polis.

La esperanza que proyectan en el $v \varepsilon \alpha v i \alpha \varsigma$ Sófocles y Eurípides, tensa un misterioso vínculo de solidaridad con la consideración de las facetas luminosas de la vejez - de las que Eurípides ofrece un paisaje verdaderamente renovado-, de esa última edad del hombre cuya forma de vida se ha ensamblado armoniosamente con el orden del universo.

En medio queda "el hombre real", el que ha marcado los derroteros de la polis hasta los albores del siglo Iv, el hombre maduro, el ciudadano por antonomasia, aquel en el que la misma polis se cimentó como estructura armónica, y que introdujo, en cambio, todos los fermentos de la desarmonía real. Así, en él afloran todos los móviles de la naturaleza humana en la praxis y todas sus contradicciones vivenciales.

Mucho antes que las artes plásticas, la literatura, la palabra escrita, con su exaltación de la primera juventud del hombre, con la presencia 
abundante en escena de ancianos, con el incipiente énfasis en las facetas luminosas junto a las sombrías de la vejez, preludia una nueva época de la historia, aquella que hemos dado en llamar helenística.

MERCEDES VflcheZ 